\title{
Large ensemble climate model simulations: introduction, overview, and future prospects for utilising multiple types of large ensemble
}

\author{
Nicola Maher ${ }^{1}$, Sebastian Milinski ${ }^{1}$, and Ralf Ludwig ${ }^{2}$ \\ ${ }^{1}$ Max Planck Institute for Meteorology, Hamburg, Germany \\ ${ }^{2}$ Department of Geography, Ludwig-Maximilians-Universität, Munich, Germany \\ Correspondence: Nicola Maher (nicola.maher@colorado.edu)
}

Published: 22 April 2021

\begin{abstract}
Single model initial-condition large ensembles (SMILEs) are valuable tools that can be used to investigate the climate system. SMILEs allow scientists to quantify and separate the internal variability of the climate system and its response to external forcing, with different types of SMILEs appropriate to answer different scientific questions. In this editorial we first provide an introduction to SMILEs and an overview of the studies in the special issue "Large Ensemble Climate Model Simulations: Exploring Natural Variability, Change Signals and Impacts". These studies analyse a range of different types of SMILEs including global climate models (GCMs), regionally downscaled climate models (RCMs), a hydrological model with input from a RCM SMILE, a SMILE with prescribed sea surface temperature (SST) built for event attribution, a SMILE that assimilates observed data, and an initialised regional model. These studies provide novel methods, that can be used with SMILEs. The methods published in this issue include a snapshot empirical orthogonal function analysis used to investigate El Niño-Southern Oscillation teleconnections; the partitioning of future uncertainty into model differences, internal variability, and scenario choices; a weighting scheme for multi-model ensembles that can incorporate SMILEs; and a method to identify the required ensemble size for any given problem. Studies in this special issue also focus on RCM SMILEs, with projections of the North Atlantic Oscillation and its regional impacts assessed over Europe, and an RCM SMILE intercomparison. Finally a subset of studies investigate projected impacts of global warming, with increased water flows projected for future hydrometeorological events in southern Ontario; precipitation projections over central Europe are investigated and found to be inconsistent across models in the Alps, with a continuation of past tendencies in Mid-Europe; and equatorial Asia is found to have an increase in the probability of large fire and drought events under higher levels of warming. These studies demonstrate the utility of different types of SMILEs. In the second part of this editorial we provide a perspective on how three types of SMILEs could be combined to exploit the advantages of each. To do so we use a GCM SMILE and an RCM SMILE with all forcings, as well as a naturally forced GCM SMILE (nat-GCM) over the European domain. We utilise one of the key advantages of SMILEs, precisely separating the forced response and internal variability within an individual model to investigate a variety of simple questions. Broadly we show that the GCM can be used to investigate broad-scale patterns and can be directly compared to the nat-GCM to attribute forced changes to either anthropogenic emissions or volcanoes. The RCM provides high-resolution spatial information of both the forced change and the internal variability around this change at different warming levels. By combining all three ensembles we can gain information that would not be available using a single type of SMILE alone, providing a perspective on future research that could be undertaken using these tools.
\end{abstract}




\section{An introduction to SMILEs}

A single model initial-condition large ensemble (SMILE; see Table 1 for a glossary of abbreviations) is a set of model simulations starting from different initial conditions but produced with a single climate model and identical external forcing. Over the last decade SMILEs have been increasingly utilised in climate science (e.g. Zelle et al., 2005; Branstator and Selten, 2009; Kay et al., 2015; Frankignoul et al., 2017; Kirchmeier-Young et al., 2017; Sanderson et al., 2018; Stolpe et al., 2018; Maher et al., 2019; Deser et al., 2020). The value of SMILEs comes from the ability to quantify and separate the internal variability of the climate system and the forced response to changes in external forcing (e.g. Kay et al., 2015; Maher et al., 2019). Additional value comes from identifying and robustly sampling extreme events (e.g. heatwaves, floods, and droughts), which potentially have large impacts on people despite their low probability of occurrence (e.g. Fischer et al., 2013; Suarez-Gutierrez et al., 2018; Haugen et al., 2018). Here, SMILEs allow a more accurate sampling of the entire probability distribution, including the tails of the distribution where extreme events occur. This sampling additionally allows for future projections of events with long return periods to be made (e.g. van der Wiel et al., 2019). Different applications require different types of SMILEs. For example, to investigate questions that involve the entire climate system, global climate model (GCM) SMILEs must be used. However, to investigate impacts at local scales, regionally downscaled climate model (RCM) SMILEs are more appropriate. Here, we provide an overview of the exciting new science published in the special issue "Large Ensemble Climate Model Simulations: Exploring Natural Variability, Change Signals and Impacts". We also present a perspective on the value of combining different types of existing SMILEs, by presenting four simple examples combining a GCM, RCM, and a natural forcing only GCM SMILE.

A large body of literature already exists using individual GCM SMILEs. The majority of studies have used the Community Earth System Model Large Ensemble (CESM-LE; Kay et al., 2015) as it has been available for the longest period of time (since 2015). Many studies have utilised the power of SMILEs to investigate the internal variability of the climate system (e.g. Fasullo and Nerem, 2016; Frankignoul et al., 2017; Smith and Jahn, 2019; Dai and Bloecker, 2019) and extreme events (e.g. Diffenbaugh et al., 2015; Gibson et al., 2017; Kirchmeier-Young et al., 2017; Tebaldi and Wehner, 2018; Wang et al., 2018). Studies have also looked into all components of the climate system, including the biosphere, with oceanic biogeochemistry included in these models (e.g. Rodgers et al., 2015; McKinley et al., 2016; Lovenduski et al., 2016; Krumhardt et al., 2017; Li and Ilyina, 2018; Schlunegger et al., 2019). More recently studies have utilised a combination of multiple SMILEs (e.g. Maher et al., 2018; Fasullo et al., 2020; Schlunegger et al., 2020; Zhou et al., 2020), allowing the assessment of model agree- ment between the SMILEs for individual scientific questions. SMILEs from seven GCMs have now become publicly available (Deser et al., 2020). In the reference paper for this model archive, Deser et al. (2020) have demonstrated that this collection "offers an unprecedented opportunity for evaluating and comparing models' forced responses and their internal variability". Despite their recent availability these SMILEs are already widely used. Some examples include the investigation of the role of internal variability and model differences in affecting future projections (Maher et al., 2020; Lehner et al., 2020; Maher et al., 2021), trends in sea surface temperature patterns (Olonscheck et al., 2020) and South American summer rainfall (Díaz et al., 2021), the decadal modulation of global warming (Liguori et al., 2020), the time of emergence of ocean biogeochemical trends (Schlunegger et al., 2020), and Arctic extremes (Landrum and Holland, 2020). These SMILEs have also been investigated for use in adaption decision making (Mankin et al., 2020), hydroclimate uncertainty in east-central Europe (Topál et al., 2020), and uncertainty in projections of global land monsoon precipitation (Zhou et al., 2020).

GCM SMILEs have been used not just to investigate scientific questions, they have also been utilised as test beds for new approaches, and tools to inform policy makers. They have been used to create an observational large ensemble (McKinnon et al., 2017; McKinnon and Deser, 2018) and test dynamical adjustment techniques (Deser et al., 2016; Lehner et al., 2017). They have also been used to develop new methodologies such as utilising the ensemble dimension for analysis (Herein et al., 2017; Maher et al., 2018, 2019; Haszpra et al., 2020a, b) and to develop and test statistical methods for isolating the forced response (Sippel et al., 2020; Wills et al., 2020). Such ensembles have additionally provided important information for policy makers, such as whether emission reductions are likely to be detectable in the coming years, or whether they could be masked by internal variability (Lehner et al., 2016; Tebaldi and Wehner, 2018; Marotzke, 2019; Spring and Ilyina, 2020).

Targeted experiments that utilise the main advantage of SMILEs, i.e. to isolate the forced response and internal variability, have also been run that both build on and complement the GCM studies. Some examples of such targeted experiments include single-forcing SMILE experiments, which have been used for detection and attribution (e.g. KirchmeierYoung et al., 2017), and RCM SMILEs, which are increasingly being used for impact studies (e.g. Leduc et al., 2016). Other complementary experiments include a large ensemble which is designed to test the sensitivity of the historical simulations to known uncertainties in aerosol forcing (Dittus et al., 2020). Atmosphere- or ocean-only large ensembles are also used to quantify the internal variability in select parts of the climate system when the rest of the climate system is fixed to observed values (Gates, 1992; Barnett et al., 1997; Penduff et al., 2014). In the following paragraphs we outline the utility of some of these targeted experiments, focusing on 
Table 1. Glossary of acronyms presented in alphabetical order for three categories: large ensemble types, Earth system acronyms, and specific climate models and modelling projects.

\begin{tabular}{|c|c|}
\hline \multicolumn{2}{|c|}{ large ensemble types } \\
\hline GCM & $\begin{array}{l}\text { global climate model; a model of the Earth system that encompasses the entire globe and includes ocean, } \\
\text { atmosphere, land, and ice components }\end{array}$ \\
\hline nat-GCM & GCM forced by natural forcing only; i.e. does not have greenhouse gas or anthropogenic aerosol forcing \\
\hline RCM & $\begin{array}{l}\text { regionally downscaled climate model; high-resolution climate model of a portion of the globe with its bound- } \\
\text { aries set using GCM output }\end{array}$ \\
\hline SMILE & $\begin{array}{l}\text { single model initial-condition large ensemble; a set of model simulations starting from different initial condi- } \\
\text { tions but produced with a single climate model and identical external forcings }\end{array}$ \\
\hline \multicolumn{2}{|c|}{ Earth system acronyms } \\
\hline DJF & boreal winter mean taken over December, January, February \\
\hline ENSO & El Niño-Southern Oscillation \\
\hline JJA & boreal summer mean taken over June, July, August \\
\hline $\max -\mathrm{SAT}$ & maximum daily surface air temperature \\
\hline $\mathrm{NAO}$ & North Atlantic Oscillation \\
\hline SAT & surface air temperature \\
\hline SEOF & snapshot empirical orthogonal function \\
\hline SST & sea surface temperature \\
\hline \multicolumn{2}{|c|}{ Specific climate models and modelling projects } \\
\hline CanESM2 & $\begin{array}{l}\text { Canadian Earth System Model (Second Generation) used as part of the Canadian Earth System Model Large } \\
\text { Ensembles and as boundary conditions for CRCM5-LE (Kushner et al., 2018; Kirchmeier-Young et al., 2017) }\end{array}$ \\
\hline CESM-LE & Community Earth System Model Large Ensemble (Kay et al., 2015) \\
\hline ClimEx & $\begin{array}{l}\text { regional large ensemble project; uses CRCM5 with CanESM2 as the boundary conditions for CRCM5-LE } \\
\text { (Leduc et al., 2019) }\end{array}$ \\
\hline CMIP & Coupled Model Intercomparison Project \\
\hline CRCM5 & Canadian Regional Climate Model, used in the CRCM5-LE (Martynov et al., 2013) \\
\hline CRCM5-LE & Canadian Regional Climate Model Large Ensemble; part of the ClimEx experiment \\
\hline EURO-CORDEX & Coordinated Downscaling Experiment - European Domain \\
\hline LAERTES-EU & Large Ensemble of Regional Climate Model Simulations for Europe (Ehmele et al., 2020) \\
\hline MIROC5 & Model for Interdisciplinary Research on Climate version 5 (Watanabe et al., 2010) \\
\hline MPI-GE & Max Planck Institute Grand Ensemble (Maher et al., 2019) \\
\hline
\end{tabular}

single-forcing and RCM ensembles as these are able to explore a wide range of possible past and future states as they include all components of the climate system.

Single-forcing SMILEs are used to separate the role of different forcings and to attribute change to different drivers. The first single-forcing SMILE was run as part of the Canadian large ensemble experiments (Kirchmeier-Young et al., 2017). This ensemble consists of a GCM run for $50 \mathrm{mem}$ bers with all forcings, 50 members with only anthropogenic aerosols, and 50 members with only natural (volcanic and solar) forcing. These experiments were completed for the period 1950-2020. The Canadian large ensemble has been used to show that extreme fire events in Canada are 1.5 to 6 times more likely under anthropogenic greenhouse gas forcing compared to a climate with natural forcing alone (Kirchmeier-Young et al., 2017). This ensemble has been used to show that anthropogenic aerosols offset the effects of anthropogenic greenhouse gases on ice cover in the midtwentieth century (Gagné et al., 2017a) and that large volcanic eruptions result in an increase in Arctic sea ice follow- 
ing the eruption (Gagné et al., 2017b). This single-forcing SMILE has also been used in combination with another SMILE (CESM-LE) to investigate the detection timescale of tropospheric warming in single-ensemble members (Santer et al., 2019). Here, the authors provided an estimate as to how uncertainty due to internal variability can affect the time required to detect patterns of change and how dependent this detection time is on different types of forcing from the singleforcing simulations.

A different type of single-forcing SMILE has also been run where an individual forcing is set to a specific value but all others remain as in the full experiment as opposed to fixing all but one forcing as in the Canadian large ensemble (Pendergrass et al., 2019). By keeping aerosols fixed at the preindustrial level Pendergrass et al. (2019) are able to identify the relationship between global warming and extreme precipitation. Previous studies have assumed that single-forcing experiments can be linearly added to recreate an all-forcing experiment result. Pendergrass et al. (2019) find that the relationship in their model is quadratic and stress that the response of extreme precipitation to aerosols is state dependent and as such the linearity assumption that is often used in the context of single-forcing experiments does not hold for this quantity. These results demonstrate the need for many different types of experiment to answer different questions and show that when there is large internal variability these experiments must be run as large ensembles.

RCMs allow for higher-resolution studies and smallerscale impact-based studies than GCMs. Internal variability is found to be larger at smaller spatio-temporal scales (Aalbers et al., 2018) demonstrating the need for RCM SMILEs that can resolve these scales and provide a large sample size (Wood and Ludwig, 2020). RCMs have the advantage the they can better represent local values. For example Leduc et al. (2019) found a better representation of extreme temperature and precipitation locally in an RCM SMILE compared to its driving GCM SMILE. In applying machine learning techniques, RCM SMILEs were of great service to detect frequencies, intensities, and the temporal dynamics of $\mathrm{Vb}$ cyclones (a specific type of cyclone associated with extreme precipitation and flooding over Europe) and the associated patterns of extreme precipitation over central Europe (Mittermeier et al., 2019). Multiple RCM SMILEs are now becoming available (e.g. Aalbers et al., 2018; Leduc et al., 2019; Kirchmeier-Young et al., 2019; Lang and Mikolajewicz, 2020), which are currently run over European and North American domains. Having multiple RCM SMILEs is important as different RCMs have different magnitudes of internal variability. This was demonstrated by von Trentini et al. (2019), who found that internal variability of a single RCM SMILE covers some but not all of the spread in a multi-model RCM ensemble.

Large ensembles of RCMs are currently used for a variety of purposes. They can be used for event attribution at higher-resolution scales than GCMs (e.g. Kirchmeier-Young et al., 2019). They can also be used to look at local changes in internal variability (e.g. Leduc et al., 2019) and projected changes in the signal-to-noise ratio of both the mean and importantly extremes (Aalbers et al., 2018; Poschlod et al., 2020b). With the availability of SMILEs, impact studies, e.g. in hydrology, can assess new ways of analysing the impacts of climate change on hydrological processes, reaching from water balance studies and flow regime changes (Poschlod et al., 2020a) to extreme events, such as floods (Willkofer and Ludwig, 2020). In order to deal with the challenges of dynamically altered extreme events under climate change, often compound events, SMILEs can introduce the concept of analysing the relevance of climate variability by means of spatially explicit and process-based models, assessing the non-linear response to multiple meteorological drivers, such as in alpine snow cover dynamics (Willibald et al., 2020) and (managed) land surface responses (Zscheischler et al., 2018). SMILEs can be used as new instruments to provide the data density and the parameter space to deal with the high process complexity and (often) data scarcity, especially when operational flood forecasting or flood risk management is targeted (Willkofer and Ludwig, 2020). For all of these cases, SMILEs can serve as a provider of coherent and standardised data, providing a very useful extension to the existing topdown modelling chain concepts, by enabling the application of artificial intelligence, machine learning, and big data concepts for impact studies.

Given the recent availability of many of the aforementioned tools, SMILEs are currently only beginning to be utilised to their full power. There are unexploited opportunities for a wide range of disciplines, such as hydrology, biogeosciences, and climate dynamics. The special issue "Large Ensemble Climate Model Simulations: Exploring Natural Variability, Change Signals and Impacts" was open to submissions which exploited these new opportunities and explored how a combined analysis of the different types of existing large ensembles can advance our knowledge in different fields. Submissions were particularly invited to use new methods to investigate these topics. The new contributions published in this special issue will be summarised in the following section.

\section{Advances in knowledge from this special issue}

The nine studies published in "Large Ensemble Climate Model Simulations: Exploring Natural Variability, Change Signals and Impacts" have utilised a wide range of types of SMILEs including seven GCM SMILEs, three RCM SMILEs, hydrological models driven by RCMs, a SMILE for event attribution (prescribed sea surface temperature), a data-assimilated SMILE, and an initialised regional SMILE. As such the studies published in this special issue cover a wide range of SMILEs that can be used for a variety of purposes. The studies fall into the following categories: (1) novel 
methods, (2) RCM large ensemble evaluation and use, and (3) impacts of global warming. They will be presented in the following sections.

\section{Novel methods}

Four novel methodologies have been published in this special issue. The study of Haszpra et al. (2020a) entitled "Investigating ENSO and its teleconnections under climate change in an ensemble view - a new perspective", uses a single GCM SMILE (CESM-LE) and the snapshot empirical orthogonal function (SEOF) analysis method to investigate the El NiñoSouthern Oscillation (ENSO) pattern and amplitude changes in each individual season by applying an SEOF across the ensemble for each month of the year. Haszpra et al. (2020a) are then able to investigate teleconnections of ENSO (taken as the first principal component) with precipitation data by computing lagged regressions between the two variables. The use of this methodology has allowed Haszpra et al. (2020a) to identify an increase in the sea surface temperature (SST) fluctuations in the ENSO region that is most pronounced in June, July, August, and September but also occurs in December, January, and February. They have also used this methodology to identify which ENSO teleconnections are projected to change and to become more pronounced in this SMILE. For example they find enhanced positive precipitation correlations with ENSO in central Africa and on the western coast of South America and a more pronounced anticorrelation over Australia and the southern edge of South America that occur in June, July, August, and September.

Hawkins and Sutton (2009) originally proposed a methodology to partition uncertainty into that from model differences, internal variability, and scenario choices using a multimodel ensemble. Lehner et al. (2020) revisit this methodology in a study entitled "Partitioning climate projection uncertainty with multiple large ensembles and CMIP5/6". Here, using seven GCM SMILEs and the Coupled Model Intercomparison Projects 5 and 6 (CMIP5 \& 6), they show that the original approach works well at global and regional scales; however, for local scales a more accurate partitioning of uncertainty is needed, which can only be achieved using the SMILEs. They additionally demonstrate that differences between CMIP5 and 6 can to some extent be reconciled by normalising projections by global mean temperature or applying a simple model weighting that targets high climate sensitivities. This shows that the differences between CMIP5 and 6 results are largely due to the high climate sensitivities found in some of the CMIP6 models.

With the newly available CMIP6 data, where some models have one ensemble member and some models have many, the question of how to combine these data in the most meaningful way has been asked. Merrifield et al. (2020) use three GCM SMILEs and 88 members of CMIP5 to provide a comprehensive evaluation of five different weighting strategies for a multi-model ensemble that includes some SMILEs in
"An investigation of weighting schemes suitable for incorporating large ensembles into multi-model ensembles". They provide a comprehensive explanation of how one would determine weights for any application and demonstrate that reasonable weights can be generated when taking both model performance and independence into account. Having such a methodology that allows the use of all available information is highly valuable and will be applicable as the new CMIP6 data becomes available. Due to its importance for upcoming analyses of the CMIP6 simulations this article was published in ESD's highlight section.

With the recent availability of many SMILEs, which vary in size from as few as 15 members to as many as 200 members, it is now important to ask the following question: "How large does a large ensemble need to be?". Milinski et al. (2020) do this, presenting a method to estimate the required ensemble size for any given problem using a single GCM SMILE (Max Planck Institute Grand Ensemble; MPIGE) and a long pre-industrial control simulation to test the method. They demonstrate that the required ensemble size depends on both the question asked and the acceptable error to the user. In general the signal (response to external forcing) and the magnitude of the internal variability determine how large the ensemble needs to be. The smallest ensemble size is needed for estimating the forced response, with a larger size needed to quantify internal variability and the highest ensemble size required to detect changes in internal variability. They also demonstrate that more members are needed for regional than global quantities. This method can be used by any scientist to identify the ensemble size required before starting their study.

These novel methodologies demonstrate the utility of SMILEs as a test bed and show that when using SMILEs traditional methods can be redefined and new methods developed, which exploit the power of large ensembles.

\section{RCM large ensemble evaluation and use}

RCM SMILEs have been used extensively in this special issue with two studies specifically evaluating how well RCMs perform. Böhnisch et al. (2020) use the 50-member Canadian Regional Climate Model Large Ensemble (CRCM5-LE) to investigate the regional response to the North Atlantic Oscillation (NAO). In particular, they investigate how well the NAO signal propagates from the GCM domain to the RCM domain in a study entitled "Using a nested single model large ensemble to assess the internal variability of the North Atlantic Oscillation and its climatic implications for Central Europe". They find that both models reproduce the NAO pattern, with the large-scale NAO propagating properly into the finer-scale RCM domain; however, the RCM produces more realistic spatial climate patterns, likely due to the additional topographic features. These features in the RCM are also found to provide value in evaluating regional NAO impacts, with the relationship between the NAO and climate over Eu- 
rope predicted to slightly weaken in the future. This study highlights how dynamically downscaling a GCM SMILE can help to understand regional impacts of major modes of internal variability by combining the advantages of a large sample size with high resolution to represent regional processes.

A multi-RCM SMILE comparison over Europe was provided by von Trentini et al. (2020). They compare three RCM SMILEs with observations in "Comparing interannual variability in three regional single model initial-condition large ensembles (SMILEs) over Europe". This study evaluates seasonal temperature, precipitation, dry periods, and heatwaves. They find that the three ensembles agree well with observations for interannual variability and that despite some model differences, the sign of projected future variability changes is similar across models. Specifically, they find an increase in summer temperature and precipitation variability as well as decreases in winter temperature and precipitation variability under strong global warming. They also find increased variability in summer in the number of heatwaves and the maximum length of a dry period in two of the three models. The study highlights the differences in projected interannual variability between ensemble members and shows that SMILEs are necessary to robustly quantify the significance of such changes.

These two studies - Böhnisch et al. (2020) and von Trentini et al. (2020) - have both demonstrated the value of using an RCM SMILE in addition to a GCM SMILE (Böhnisch et al., 2020) and provided some confidence in projections across the European domain (von Trentini et al., 2020).

\section{Impacts of global warming}

Many studies in this special issue address the changing probabilities of extreme events and their impacts under a changing climate. SMILEs are the perfect tool to investigate such events because they sample the probability distribution at each time step and allow assessment of changes in the probabilities of events such as floods, droughts, and heatwaves. In this special issue Canadian winter hydrometeorological extreme events are investigated by Champagne et al. (2020), European flooding events are investigated by Ehmele et al. (2020), and fire and drought in Asia are investigated by Shiogama et al. (2020).

Champagne et al. (2020) published "Winter hydrometeorological extreme events modulated by large-scale atmospheric circulation in southern Ontario". In this study they use a single RCM SMILE (CRCM5-LE) to create a new winter compound index to investigate the contribution of the combination of rain and snowmelt to extreme events. They then use the output from the RCM SMILE as input to a hydrological model to identify the necessary conditions needed for high flows to occur in three southern Ontario watersheds and to project their future evolution. They find that the RCM output is realistic when compared to observational data and project an increase in the future number of heavy rain and warm events associated with high flows particularly in the vicinity of Lake Erie, especially when there are high $500 \mathrm{mb}$ geopotential height anomalies centred on the eastern Great Lakes and the Atlantic Ocean. Using the RCM SMILE they are able to investigate how the internal variability of climate will modulate the future evolution of these hydrometeorological extremes and show that the increase in events can be amplified or attenuated depending on the location of pressure systems modulated by internal variability.

Ehmele et al. (2020) use a single RCM SMILE (Large Ensemble of Regional Climate Model Simulations for Europe; LAERTES-EU) that consists of both long-term and initialised simulations as well as runs that assimilate reanalysis data to look at "Long-term variance of heavy precipitation across central Europe using a large ensemble of regional climate model simulations". They find that the model represents observed extreme precipitation well. When considering future projections, the upcoming decade shows a continuation of past tendencies in Mid-Europe, with increasing heavy precipitation, with no clear signal for the Alps. Additionally they use the power of the large ensemble to show that there are phases of increased and decreased heavy precipitation that are due to internal variability alone. Generally, they emphasise the benefit of RCM SMILEs for an improved estimation of extreme values, building on robust statistics.

A large event attribution ensemble (Model for Interdisciplinary Research on Climate 5; MIROC5), where sea surface temperatures and ice are prescribed, is used to demonstrate the role of historical anthropogenic warming on droughts and fires in equatorial Asia (Shiogama et al., 2020). In the study entitled "Historical and future anthropogenic warming effects on droughts, fires and fire emissions of $\mathrm{CO}_{2}$ and $\mathrm{PM}_{2.5}$ in equatorial Asia when 2015-like El Niño events occur", Shiogama et al. (2020) show significant increases in burned area, carbon dioxide, and $\mathrm{PM}_{2.5}$ emissions at 1.5 and $2{ }^{\circ} \mathrm{C}$ of warming, with the chance of exceeding the large 2015 event reaching $100 \%$ under $3{ }^{\circ} \mathrm{C}$ of warming. They also argue for including fires in future climate modelling scenarios as these can affect global carbon dioxide emissions.

Finally the previously discussed papers of Böhnisch et al. (2020) and Haszpra et al. (2020a) also investigate impacts of the modes of variability: NAO and ENSO respectively. Böhnisch et al. (2020) find an increasing the frequency of a negative NAO that favours colder and harsher winters in Europe. Haszpra et al. (2020a) demonstrate that some ENSO teleconnections can change, with some increasing in strength while others decrease, which will have different impacts in different regions. An example of the changes they find is an increase in precipitation teleconnections between ENSO and Australia and Africa in their respective winters at the end of the century.

Overall these studies on changing events and their impacts are made possible by the use of SMILEs, where extreme events are well sampled and changes in modes of variability can be separated from large internal variability. These stud- 
ies are relevant for policy and planning, with Ehmele et al. (2020) demonstrating high variability in precipitation over different decades in Europe, Champagne et al. (2020) showing changes in flood risk in Ontario in their study, and Shiogama et al. (2020) finding an increase in the risk of large fires and their impacts in equatorial Asia under increasing warming.

\section{Perspectives on new tools and their value}

There are now many SMILEs available for use in the climate community. These include GCM SMILEs, atmosphere- and ocean-only SMILEs, single forced SMILEs, SMILEs forced with all except one forcing, RCM SMILEs, and SMILE experiments with different sets of forcing such as varying aerosols. In this section we present some simple examples to investigate the value of combining different types of SMILEs and demonstrate how future research can benefit from using the SMILEs which are already available. To do this we use the Canadian Earth System Model Large Ensemble (CanESM2; Kirchmeier-Young et al., 2017; Kushner et al., 2018) because it has 50 members of both the full forced ensemble (1950-2100; historical and RCP8.5) and 50 members of natural-only forcing (solar and volcanic forcing; 1950-2020). These SMILEs are henceforth referred to as GCM and nat-GCM. We combine the GCM and nat-GCM with the Canadian Regional Climate Model Large Ensemble (CRCM5-LE as part of the ClimEx project; Leduc et al., 2019), which uses the Canadian Regional Climate Model (12km resolution CRCM5; Martynov et al., 2013; Šeparović et al., 2013) with the CanESM2 GCM SMILE with all forcings used as boundary conditions. We utilise the European domain from this SMILE. This SMILE will be referred to as RCM for the rest of this study.

To investigate the value of combining the GCM and RCM SMILEs we will evaluate changes in both near-surface air temperature (SAT) and precipitation at multiple warming levels. The warming levels are $1 \mathrm{~K}$ (2002), $1.5 \mathrm{~K}$ (2015), $2 \mathrm{~K}$ (2028), $3 \mathrm{~K}$ (2048), and $4 \mathrm{~K}$ (2067). The years at which each warming level occurs are found using the ensemble mean from the GCM as compared to the pre-industrial control. We use an 11-year window centred on each warming level to analyse the data. Projected changes are always shown relative to the $1 \mathrm{~K}$ level (similar to the present day; Allen et al., 2018) and are computed individually for each ensemble member. This choice allows us to investigate future changes above the present day. This is particularly relevant in light of the targets of 1.5 and $2 \mathrm{~K}$ set by the Paris Agreement. In addition to SAT and precipitation we use the variable maximum daily temperature (tasmax in the ensemble output), henceforth referred to as max-SAT. For the GCM this variable is output as the monthly mean of the daily maximum temperature. We average the daily data from the RCM to be comparable. For the analyses presented in this editorial summer is computed as the average of June, July, and August (JJA) and winter as the average of December, January, and February (DJF).

The ensemble mean SAT and precipitation at $1 \mathrm{~K}$ of warming are shown for the GCM and RCM SMILEs in Fig. 1. The continental outlines highlight the resolution difference between the GCM and the RCM. The patterns of both SAT and precipitation are broadly similar between the GCM and the RCM, with warmer temperatures to the south and more precipitation to the north-west of the domain, particularly over the United Kingdom and western Norway. Figure 1 also shows that the increased resolution of the RCM allows the local patterns to be better resolved and highlights the effects of features such as coastlines and mountains. Subtracting the GCM from the RCM shows that the RCM tends to be slightly cooler and wetter than the GCM. While there has been no comprehensive validation of whether the GCM or RCM is more realistic, when compared to observations over Europe, Leduc et al. (2019) found a better representation of extreme precipitation and local extremes in the RCM than the GCM, particularly over coastal and mountain regions, due to the higher resolution. In general due to their higher-resolution RCMs provide a more realistic representation of smaller scales, such as land-sea contrasts and orography and, at higher resolutions, lakes and rivers (e.g. Lucas-Picher et al., 2017; Rummukainen, 2010; Christensen and Kjellström, 2020; Feser et al., 2011). This makes RCMs more suited for looking at impacts at local scales and more reliable than GCMs when looking at small regions and events on shorter timescales (Rummukainen, 2016).

To demonstrate the utility of combining different types of SMILE we consider the following simple examples:

1. We ask whether the SAT and precipitation responses over Europe are linear with global warming in both the GCM and RCM.

2. We investigate SAT, max-SAT, and precipitation projections in a subset of European cities in both the GCM and $\mathrm{RCM}$ at $1.5,2,3$, and $4 \mathrm{~K}$ global warming. These cities are shown in Fig. 1 and are chosen due to their location near the coastline or in mountainous regions, where the increased resolution of the RCM may provide additional information.

3. We investigate whether there are forced changes and, if so, their drivers in summer SAT variability at 1.5 and $4 \mathrm{~K}$, by combining the GCM, nat-GCM, and RCM

4. Finally we investigate the European seasonal response to large volcanic eruptions using all three SMILEs.

\section{Regional response to global warming}

In this section we ask whether the European SAT and precipitation responses are linear with global warming. By using the GCM SMILE we can pinpoint specifically when the model 

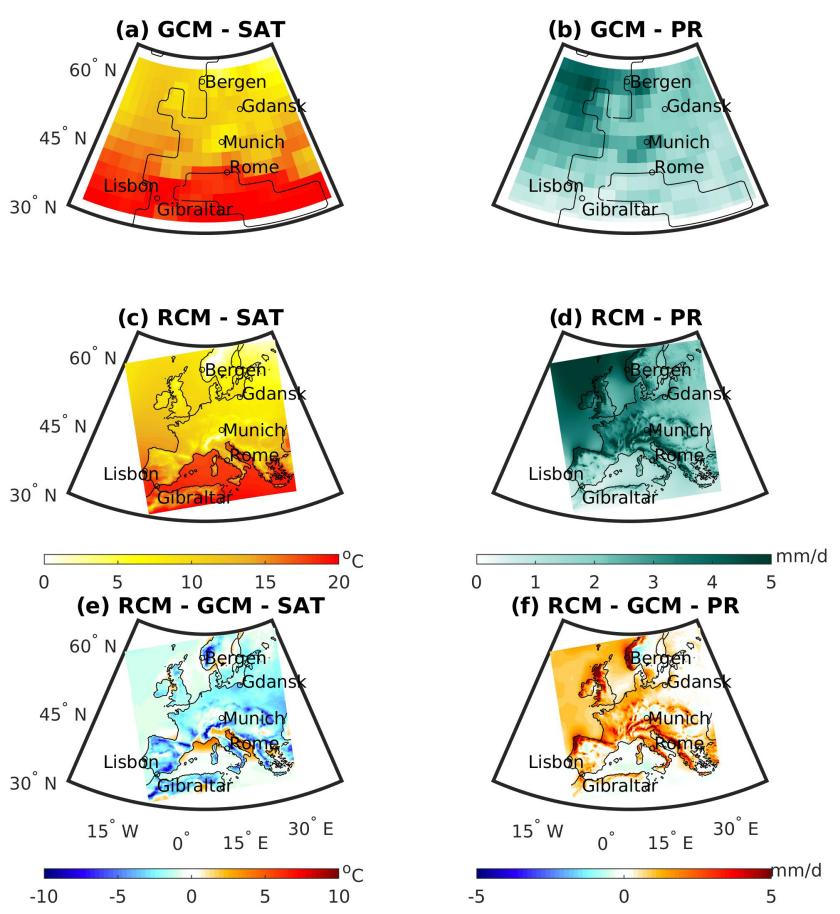

Figure 1. Ensemble mean surface air temperature (SAT) and precipitation in the GCM (a, b) and RCM (c, d) SMILEs over Europe at $1 \mathrm{~K}$ warming (2002). The difference between the RCM and GCM SMILEs is shown in (e) and (f). We use an 11-year window around the warming year to analyse the data. The cities investigated in Figs. 3 and 4 are shown on the maps. Continental borders are plotted for each model's native grid.

has reached a given level of global warming. By computing the ensemble mean at each warming level, we can precisely identify the forced response at each warming level in both the GCM and RCM. Due to the large ensemble sizes, differences between the GCM and RCM can be directly attributed to differences in the forced response between the two SMILEs. Using an RCM for climate projections has previously been shown to both provide additional value, but to also introduce additional biases (Jacob et al., 2020). The added value has been shown to come from better representation of physical mechanisms as well as the better representation of underlying topography (Dudhia, 2014; Mearns et al., 2013; Di Luca et al., 2013; Evans and McCabe, 2013), suggesting the RCM projections may be regionally more reliable than the GCM.

We find that the scaled SAT and precipitation patterns at $1.5 \mathrm{~K}$ are very similar in the GCM and RCM (Fig. 2a, c, e, g). These patterns also resemble those found in the Coordinated Downscaling Experiment in the European Domain (EUROCORDEX) experiment (Jacob et al., 2018). By looking at the scaled $4 \mathrm{~K}$ response as compared to the scaled $1.5 \mathrm{~K}$ response (Fig. 2b, f), we find that the SAT response is slightly non-linear with south-western Europe warming more at $4 \mathrm{~K}$ and northern and eastern Europe warming less relative to the scaled $1.5 \mathrm{~K}$ response. The RCM and GCM agree well on this non-linearity. When considering precipitation, the response is again non-linear (Fig. 2d, h), with the increase in precipitation over northern Europe not as large at $4 \mathrm{~K}$ as at $1.5 \mathrm{~K}$, but the decrease over southern Europe larger. While there is agreement between the GCM and RCM on the broad-scale pattern, the RCM is needed to resolve the local precipitation non-linearity and the response over southern Europe. The result that there is more added value of the RCM for precipitation than SAT is in agreement with previous work as precipitation is more affected by orography and small-scale processes than SAT (Lucas-Picher et al., 2017; Christensen and Kjellström, 2020; Feser et al., 2011; Rummukainen, 2016).

\section{Projections in individual European cities}

Given that the RCM provides the most additional information at local scales, particularly near the coastlines and orography, we next investigate some major cities across Europe (shown in Fig. 1), all of which are near the coastline or orography. Here, we investigate how the warming in an individual city compares to the global mean warming by utilising the power of the SMILEs and computing the forced response in each city. For example if we take a city such as Rome, we can ask the question of whether we expect Rome to warm more or less than the global mean. We can then ask whether this relative warming is linear with global warming; i.e. if at $2 \mathrm{~K}$ warming Rome warms more than the global mean, does it warm the same amount more at $4 \mathrm{~K}$ ? Finally because we are using SMILEs we can look at the range of warming in Rome that we could observe due to internal variability. For example if the mean warming is the same as the global mean warming, how much more or less warming than the mean could we observe due to internal variability? Here, we will assess if the answers to these questions differ between the GCM and RCM.

We find a range of results across the three cities (Fig. 3). When we consider the ensemble mean warming, Lisbon warms less than the global mean, while Rome warms slightly more and Gdańsk warms similarly. Rome and Gdańsk warm more in summer and in the summer maximum temperature than the global mean, especially at larger levels of warming. This means that someone living in these cities would likely experience more warming than the global mean level would suggest. Surprisingly, we find that the RCM shows less nonlinearity in the relative warming than the GCM. This gives slightly lower projected temperatures and a slightly more promising outlook when using the RCM as compared to the GCM.

We next consider the seasonal cycle. Here, an increase means that summer warms more than winter. The seasonal cycle increases in Lisbon and Rome. This change and the internal variability of the change are slightly smaller in the RCM than the GCM, suggesting that the local range of possible observed changes could be smaller than expected from the GCM. Where the internal variability no longer crosses the 

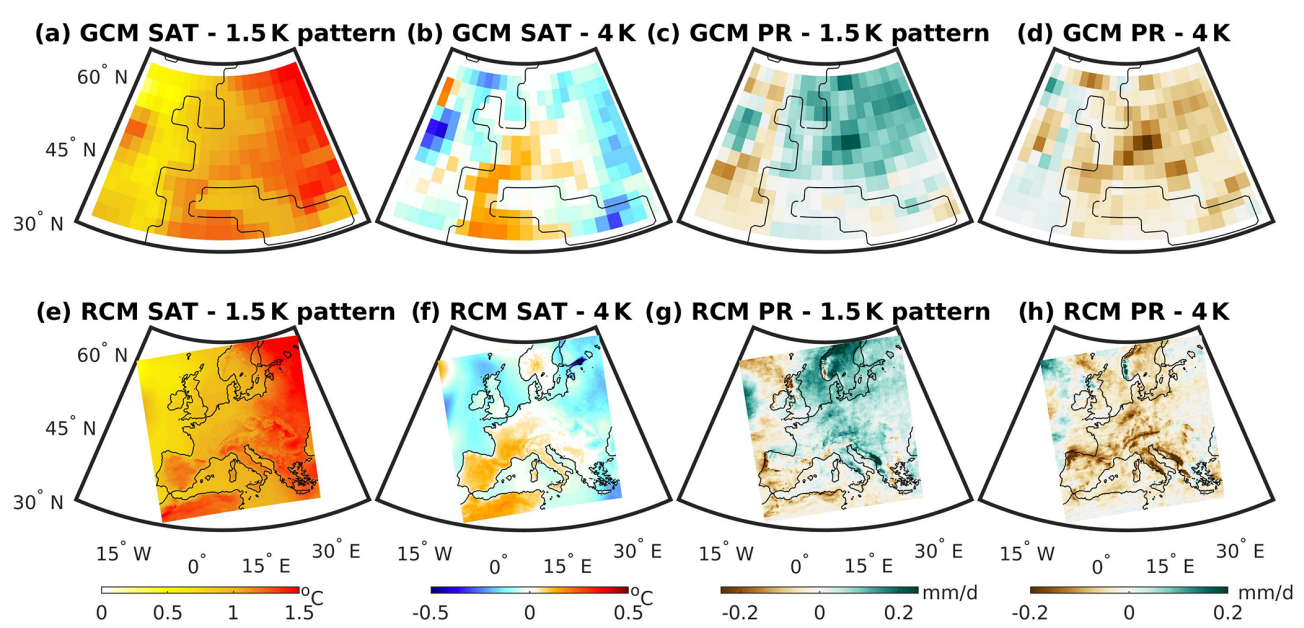

Figure 2. Surface air temperature (SAT) and precipitation change over Europe scaled by the globally averaged SAT change. (a) Scaled SAT change at $1.5 \mathrm{~K}$ in the GCM, (b) scaled SAT change at $4 \mathrm{~K}$ with scaled SAT change at $1.5 \mathrm{~K}$ subtracted in the GCM, (c) scaled precipitation change at $1.5 \mathrm{~K}$ in the GCM, (d) scaled precipitation change at $4 \mathrm{~K}$ with scaled SAT change at $1.5 \mathrm{~K}$ precipitation in the GCM, (e) Scaled SAT change at $1.5 \mathrm{~K}$ in the RCM, (f) scaled SAT change at $4 \mathrm{~K}$ with scaled SAT change at $1.5 \mathrm{~K}$ subtracted in the RCM, (g) scaled precipitation change at $1.5 \mathrm{~K}$ in the RCM, and (h) scaled precipitation change at $4 \mathrm{~K}$ with scaled SAT change at $1.5 \mathrm{~K}$ precipitation in the RCM. Changes are computed relative to the pattern at $1 \mathrm{~K}$ of global warming. Continental borders are shown for the each model's native grid. The scaled changes in panels (a) and (d) are computed as the pointwise SAT at $1.5 \mathrm{~K}$ minus the pointwise SAT at $1 \mathrm{~K}$ dived by the global mean warming above $1 \mathrm{~K}$ (i.e. $0.5 \mathrm{~K}$ ) in each individual ensemble member. The patterns in (b) and (f) use the same calculation at $4 \mathrm{~K}$, with the patterns from (a) and (e) subtracted from them. The ensemble mean is taken prior to the subtraction. The same process is computed in the right-hand panels for precipitation.

zero line (e.g. 3-4 K warming for Rome and Lisbon), we expect to see an increase in the seasonal cycle in all members, although the magnitude of the change depends on how the system evolves in each individual member. This is an important advantage of using SMILEs as we can assess the range of possible futures that could be observed due to the combination of increasing greenhouse gases and internal variability.

Finally we investigate how precipitation is projected to change in a city on the coastline with high mean precipitation (Bergen, Fig. 4a, b), a city on the coastline with low mean precipitation (Gibraltar, Fig. 4e, f), and a city surrounded by high orography (Munich, Fig. 4c, d). We find limited changes in the forced response for both mean and summer precipitation in all three cities as compared to the precipitation at $1 \mathrm{~K}$ of warming. There is little difference in the mean changes between the GCM and RCM. However, the RCM can have very different internal variability than the GCM. We find larger variability in the RCM over Bergen. This means that while there is little mean change in Bergen, at any warming level the city could observe a $2.5 \mathrm{~mm} / \mathrm{d}$ decrease or $3 \mathrm{~mm} / \mathrm{d}$ increase in both the mean and summer mean precipitation in any given year due to internal variability alone. This demonstrates the additional value of an RCM SMILE in planning for potential observed changes in local locations.

\section{Insights into forced changes in temperature variability}

Using SMILEs we are now able to quantify changes in internal variability at different warming levels. This was not previously possible with single runs of climate models. By pooling the summer data for all ensemble members for the 11-year window around each warming level we can calculate the internal variability at each grid point in the European domain for each individual warming level. To do this we take a standard deviation across the pooled data. Figure 5 shows the GCM summer SAT internal variability at $1.5 \mathrm{~K}$ and the difference between the GCM and the RCM and the nat-GCM. We find that the GCM has slightly less variability over northwestern Europe as compared to the nat-GCM, suggesting that summer variability at $1.5 \mathrm{~K}$ is decreased over this region as compared to natural unforced variability alone. The RCM generally has less variability than the GCM, which indicates that the GCM might overestimate summer SAT variability over Europe. We then consider the change in variability at $4 \mathrm{~K}$ as compared to $1.5 \mathrm{~K}$ in both the GCM and RCM. We find a projected increase in variability over all of the European land mass, except Portugal and Spain, that is larger in the RCM than the GCM. This tells us that local processes in the RCM result in a larger increase in summer temperature variability, although the overall increase in both the RCM and GCM displays the same pattern. 

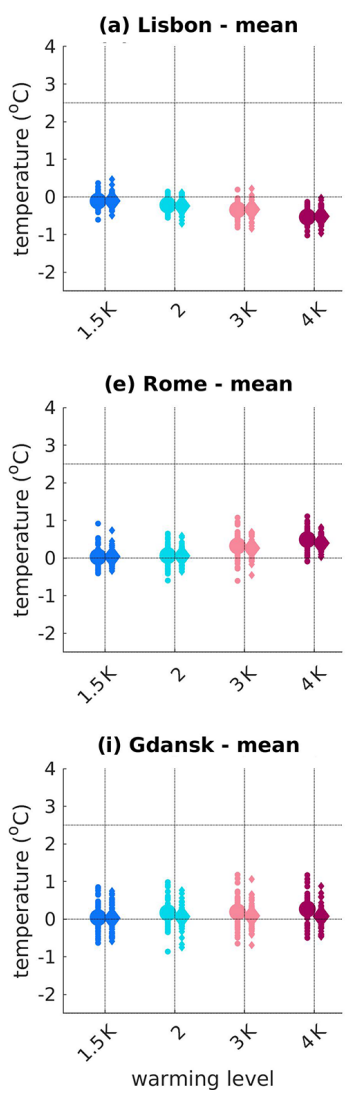
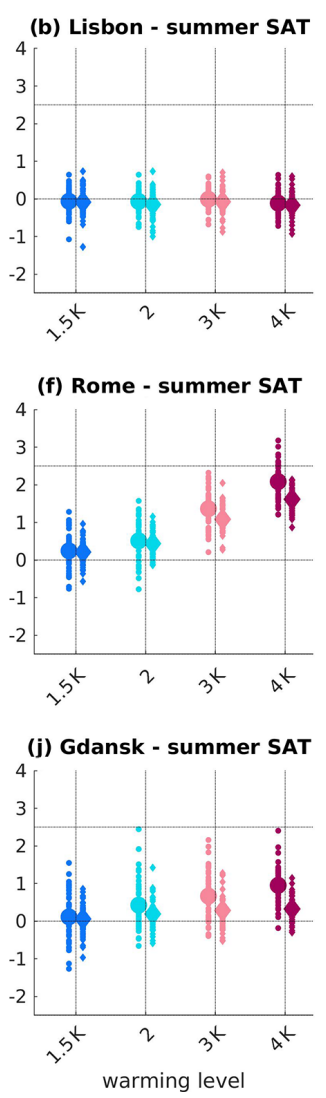
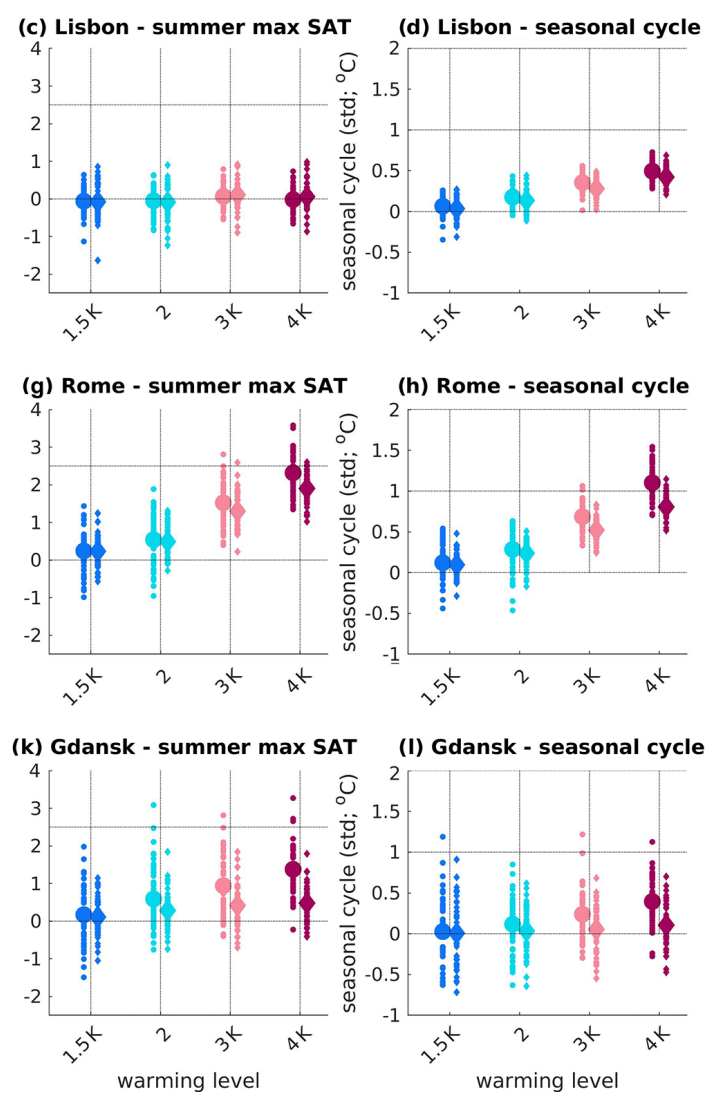

Figure 3. Annual-mean surface air temperature (SAT) (a, e, i), summer SAT (b, f, j), and summer max-SAT (c, g, k) and the seasonal cycle change (d, h, l) shown at each warming level relative to $1 \mathrm{~K}$ of global warming. Shown for the GCM (circles) and the RCM (diamonds). Each ensemble member is shown in the small symbols with the ensemble mean in the large symbol. Shown for (a-d) Lisbon $\left(38.7223^{\circ} \mathrm{N}\right.$, $\left.9.1393^{\circ} \mathrm{W}\right),(\mathbf{e}-\mathbf{h})$ Rome $\left(41.9028^{\circ} \mathrm{N}, 12.4964^{\circ} \mathrm{E}\right)$, and (i-l) Gdańsk $\left(54.3520^{\circ} \mathrm{N}, 18.6466^{\circ} \mathrm{E}\right)$. Each ensemble members change is computed relative to itself at $1 \mathrm{~K}$, with the global warming above $1 \mathrm{~K}$ then subtracted for all variables except the seasonal cycle. The seasonal cycle is computed as the standard deviation over all 12 months after the 11-year period has been averaged.

\section{Attributing climate responses to volcanic eruptions}

By combining the GCM, RCM, and nat-GCM SMILEs we can further investigate the response of both SAT and precipitation to large volcanic eruptions over Europe. To investigate the response to volcanoes previous studies have shown that many ensemble members are needed to tease out the forced response (Maher et al., 2015; Pausata et al., 2015; Bittner et al., 2016; Milinski et al., 2020), meaning that SMILEs are an ideal tool to investigate this question.

By combining the GCM and RCM SMILEs after volcanic eruptions we can investigate the local structure of both the temperature and precipitation responses over Europe to these eruptions. Figure 6 demonstrates that the RCM and GCM give broadly similar response patterns but again that the RCM provides higher-resolution local information. Computationally GCMs are much more efficient than RCMs, making the GCM the perfect tool to run the natural-only forcing experiment with. By using nat-GCM we can precisely tease out which part of GCM and by proxy RCM response is forced by the volcanoes and what the contribution of other factors such as anthropogenic emissions is. The volcanic cooling is underestimated in the GCM and RCM SMILEs when using the standard method of removing the 5-year mean prior to the eruption, particularly in summer (e.g. Fischer et al., 2007; Maher et al., 2015; Liu et al., 2018; Zuo et al., 2018), as is demonstrated by the much stronger cooling found in the nat-GCM SMILE. This demonstrates that using nat-GCM adds to the GCM analysis by better identifying the full cooling response to volcanic eruptions. By using the nat-GCM we can conclude that cooling occurs in both the first summer and winter after the eruptions with more cooling occurring in summer. When considering the precipitation response, there is a general increase in the nat-GCM in summer and a decrease in winter over the domain. The non-volcano response is fairly similar in the two seasons leading to an amplification of the winter pattern and a damping of the summer pattern in the GCM and RCM that can only be identified by combining these SMILEs with the nat-GCM.

By using nat-GCM SMILE we can investigate these volcanic responses even further. While most previous studies 

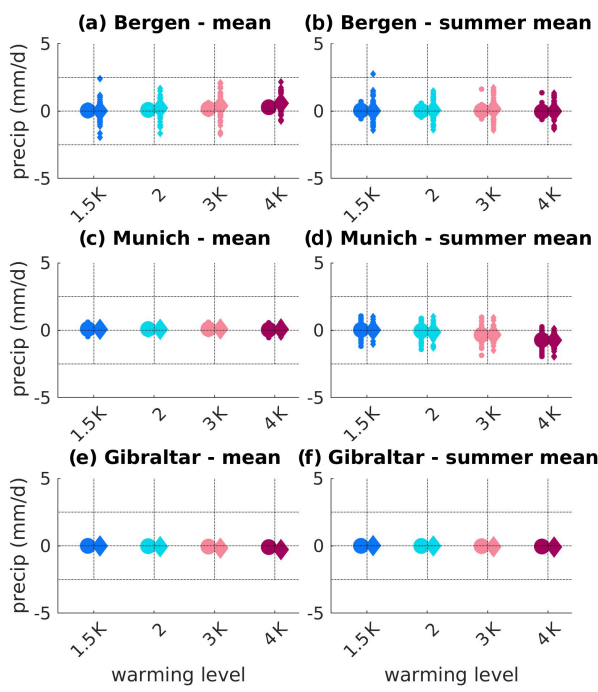

Figure 4. Annual-mean precipitation (a, c, e) and summer precipitation $(\mathbf{b}, \mathbf{d}, \mathbf{f})$ shown at each warming level relative to $1 \mathrm{~K}$ of global warming. Shown for the GCM (circles) and the RCM (diamonds). Each ensemble member is shown in the small symbols with the ensemble mean in the large symbol. Shown for (a-b) Bergen $\left(60.3913^{\circ} \mathrm{N}, 5.3221^{\circ} \mathrm{E}\right),(\mathbf{c}-\mathbf{d})$ Munich $\left(48.1351^{\circ} \mathrm{N}, 11.5820^{\circ} \mathrm{E}\right)$, and (e-f) Gibraltar $\left(36.1408^{\circ} \mathrm{N}, 5.3536^{\circ} \mathrm{W}\right)$. Each ensemble members change is computed relative to itself at $1 \mathrm{~K}$.

could only look at multi-eruption mean response due to small ensemble sizes (e.g. Maher et al., 2015), we can investigate individual eruption responses in nat-GCM (Fig. 7). We find that El Chichón and Pinatubo have qualitatively more similar responses over Europe, while Agung shows different patterns for both SAT and precipitation. This agrees well with a new study using a different SMILE (MPI-GE) that shows that the intertropical convergence zone and ENSO response is different after Agung due to its aerosol being located in the Southern Hemisphere as compared to the other two eruptions (Ward et al., 2020). By using the nat-GCM we can simply tease out the response over Europe to each individual eruption without needing to remove the anthropogenic signal. Here, using the three SMILEs together gives us additional insight into the European response to volcanic eruptions.

\section{SMILEs - new frontiers in climate science}

The utility of different types of SMILEs has been highlighted in the studies published in this special issue, "Large Ensemble Climate Model Simulations: Exploring Natural Variability, Change Signals and Impacts". Lehner et al. (2020) demonstrate where and when internal variability is most important for projections using seven GCM SMILEs. Böhnisch et al. (2020) show that RCM SMILEs are important due to the large range of results that can be obtained in single realisations, with von Trentini et al. (2020) finding that it is important to have multiple RCM SMILEs due to the com- bined role of both internal variability and model differences in causing the uncertainty that occurs on the regional scale as well as the global scale. Examples that use SMILEs to drive a hydrological model, event attribution large ensembles, and a combination of data-assimilated, initialised, and long-term large ensemble simulations and their utility are given by Champagne et al. (2020), Shiogama et al. (2020), and Ehmele et al. (2020) respectively, with Champagne et al. (2020) demonstrating how important SMILEs are for investigating the range of projections we may observe and Ehmele et al. (2020) highlighting the benefit of SMILEs for improving the estimation of extreme values.

While Deser et al. (2020) have demonstrated the utility of having comparable GCM SMILEs from different models, in this editorial we build on this to show the value of having multiple types of SMILEs. We use three types of SMILE (GCM, RCM, and nat-GCM), which all stem from the same modelling chain. While there is a wealth of literature on the added value of RCMs to GCMs that demonstrates that RCMs are most valuable when looking at smallerscale projections around land-sea regions and orography as well as short-timescale events (Rummukainen, 2016), RCM SMILEs have only recently begun to be utilised in the literature. Single-forcing SMILEs (such as nat-GCMs) have been used more extensively to focus on and identify the role of individual forcings in driving specific events or changes (e.g Kirchmeier-Young et al., 2017; Gagné et al., 2017a, b; Pendergrass et al., 2019) but could be increasingly used in combination with other types of SMILEs, such as RCMs.

By using SMILEs we are able to precisely quantify the forced response, and internal variability in an individual model. By combining this key advantage with the three different types of SMILE we have shown that the European SAT and precipitation responses are non-linear with global warming, with the southern European and local-scale non-linearity in precipitation only identifiable using the RCM SMILE in combination with the driving GCM SMILE. We have investigated individual cities under different levels of warming and identified that the internal variability in precipitation can be quite different in the RCM compared to the GCM, demonstrating the added value of the RCM SMILE at local scales. By using SMILEs we have also been able to quantify forced changes in the summer SAT variability itself. Combining the GCM, RCM, and nat-GCM we have shown where changes in variability can be attributed to increasing greenhouse gas forcing and that the RCM has a larger increase in variability over Europe than the GCM. Finally using all three SMILEs we have investigated the European response to volcanic forcing. In this case the RCM provides a better-resolved response locally but the nat-GCM gives the most additional value and allows us to identify the response to the each eruption individually, while the GCM shows how this volcanic forcing combined with global warming impacts what could be observed. 

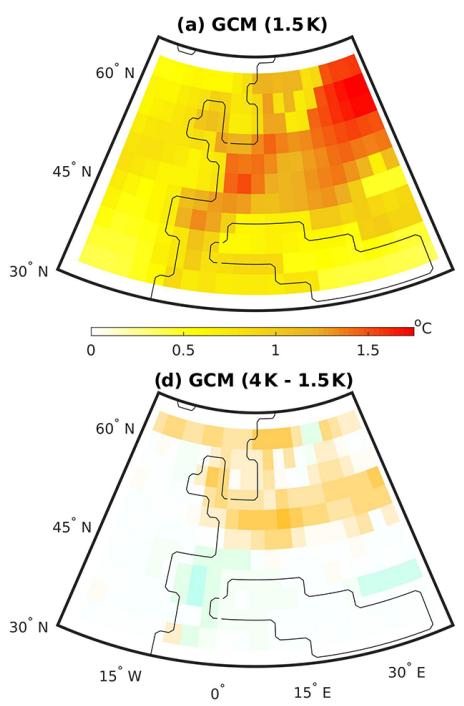

$-0.8-\frac{1}{2}-0.6$
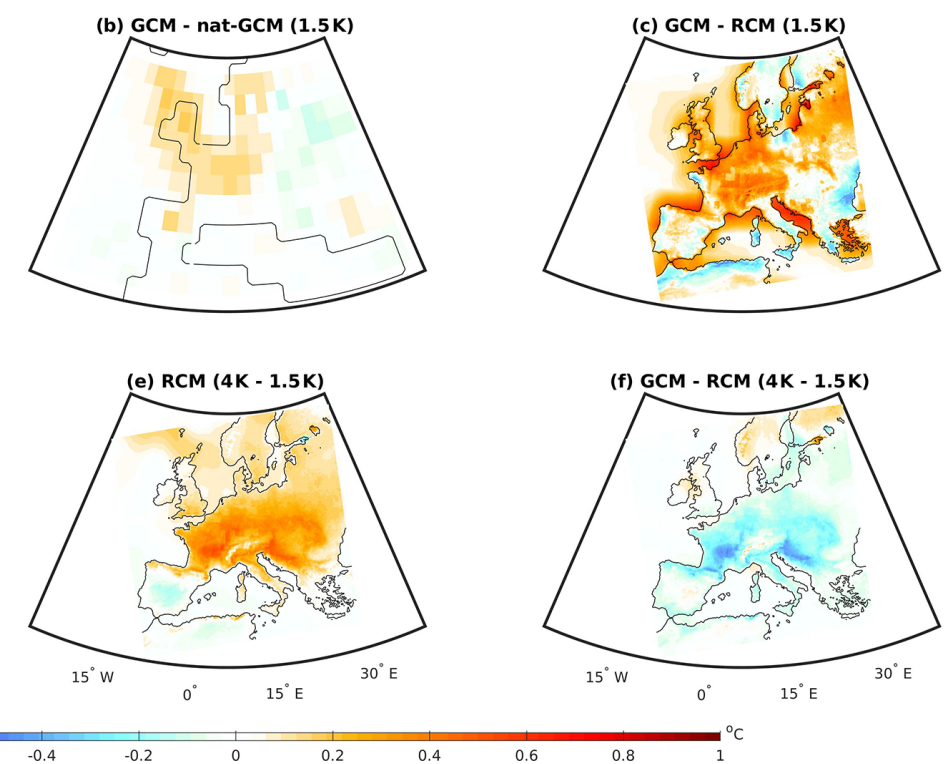

Figure 5. Summer surface air temperature (SAT) variability in (a) the GCM at $1.5 \mathrm{~K}$ warming, (b) difference between GCM and the nat-GCM at $1.5 \mathrm{~K}$ warming, (c) difference between the GCM and RCM at $1.5 \mathrm{~K}$ warming, (d) the GCM at $4 \mathrm{~K}$ warming, (e) the RCM at $4 \mathrm{~K}$ warming, and (f) difference between the GCM and RCM at $4 \mathrm{~K}$ warming. Before the RCM is subtracted from the GCM, the GCM is regridded to the RCM grid. We use an 11-year window around each warming year to analyse the data. SAT variability is calculated as the standard deviation across the pooled summer (mean over June, July, and August each year) SAT from all ensemble members and all years in the time period. The forced response in the mean state is removed by removing the ensemble mean for each summer from each ensemble member prior to the variability calculation. Continental borders are shown for each model's native grid.
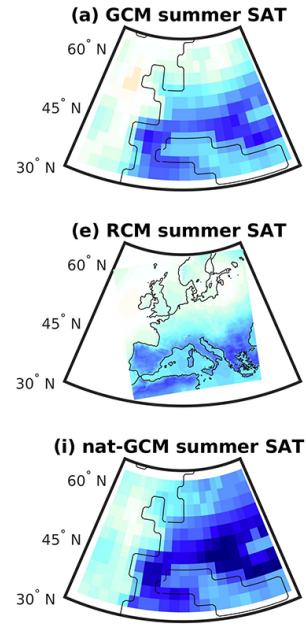

(m) GCM minus nat-GCM summer SAT

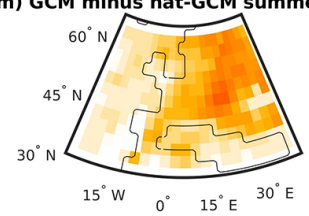

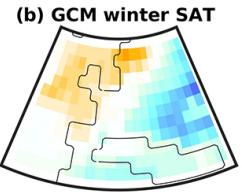

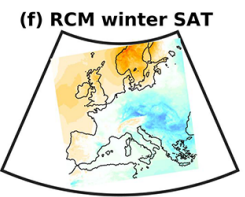

(j) nat-GCM winter SAT

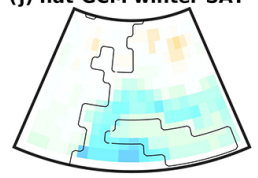

(n) GCM minus nat-GCM winter SAT

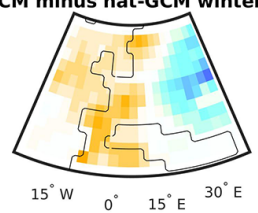

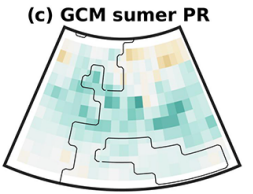

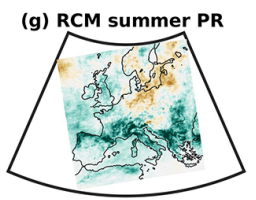

(k) nat-GCM summer PR

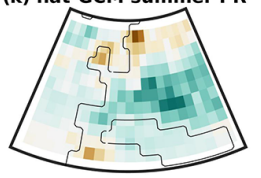

(o)

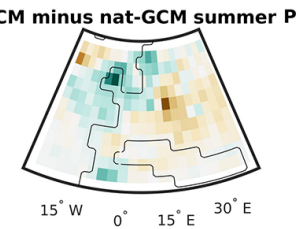

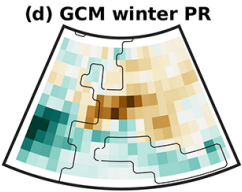
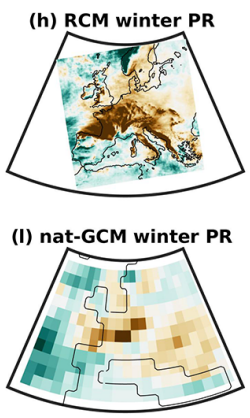

(p) GCM minus nat-GCM winter PR
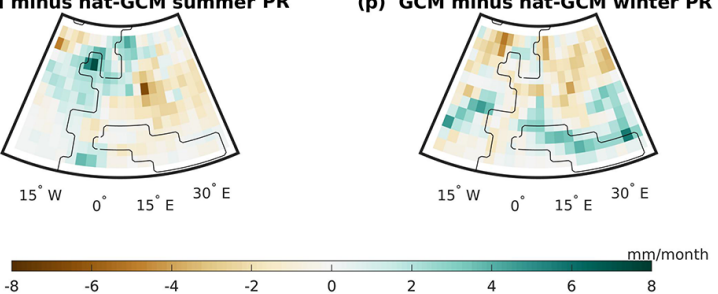

Figure 6. Multi-eruption mean surface air temperature (SAT) for the summer (a, e, i, m) and winter $(\mathbf{b}, \mathbf{f}, \mathbf{j}, \mathbf{n})$ and precipitation for summer $(\mathbf{c}, \mathbf{g}, \mathbf{k}, \mathbf{o})$ and winter $(\mathbf{d}, \mathbf{h}, \mathbf{l}, \mathbf{p}) 1$ year after the eruption. Shown for the GCM (a-d), RCM (e-h), nat-GCM (i-l), and the residual forcing ( $\mathbf{m}-\mathbf{p}$; GCM minus nat-GCM). Anomalies are shown relative to the 5-year period directly prior to the eruptions. The three eruptions in the multi-eruption mean are Agung, El Chichón, and Pinatubo; the years plotted are 1964, 1983, and 1992 respectively (for winter this is 1963/64, 1982/83, and 1991/92) similar to Fischer et al. (2007). Continental borders are shown for each individual model. 

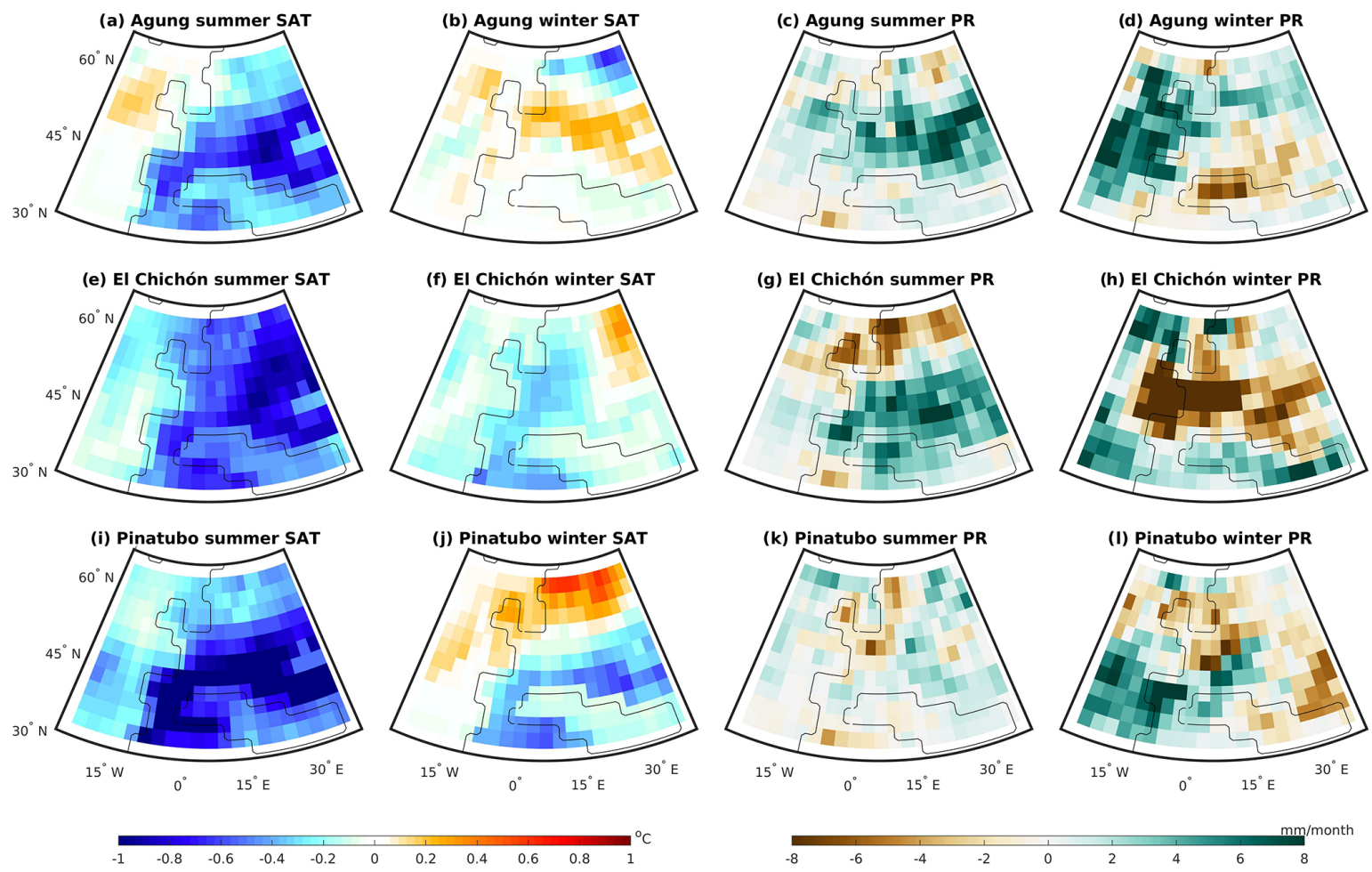

Figure 7. Surface air temperature (SAT) for the summer $(\mathbf{a}, \mathbf{e}, \mathbf{i})$ and winter $(\mathbf{b}, \mathbf{f}, \mathbf{j})$ and precipitation for summer $(\mathbf{c}, \mathbf{g}, \mathbf{k})$ and winter $(\mathbf{d}, \mathbf{h}, \mathbf{l})$ 1 year after (a-b) Agung, (c-d) El Chichón, and (e-f) Pinatubo shown for the nat-GCM. Anomalies are shown relative to the 5-year period directly prior to the eruptions. The years plotted are 1964, 1983, and 1992 respectively (for winter this is 1963/64, 1982/83, and 1991/92) similar to Fischer et al. (2007). Continental boundaries are shown for the GCM native grid.

Here, we have shown that dynamically downscaling a GCM SMILE provides valuable additional information, particularly at local scales compared to the GCM. The computationally cheaper GCM is needed to run the RCM and to compute the warming levels. It also has the advantage that additional sensitivity experiments are affordable. With the modelling chain of GCM, RCM, and targeted GCM (e.g. nat-GCM), we can better interpret some of the signals in the $\mathrm{RCM}$, thus utilising the unique power of the RCM and targeted GCM experiments.

With the many SMILEs now becoming available, new studies that combine different types of ensemble will increasingly be able to answer unsolved questions in climate science, particularly focusing on separating and quantifying the forced response to external forcing and internal variability. Additionally due to the large computational expense of SMILE experiments, utilising the data available and combining experiments is more accessible to many users. Using simple examples and a small subset of the data available, in this editorial we have shown some interesting applications of combining multiple types of large ensemble. Future studies will be able to go well beyond this and push the boundaries of our understanding of internal variability and the forced response to external forcing at both global and local scales due the wealth of new data that has become available. The new methods published in the special issue already begin to push the boundaries of what can be done using large ensembles (Haszpra et al., 2020a; Lehner et al., 2020; Merrifield et al., 2020; Milinski et al., 2020) as do those that combine different ensemble types (Merrifield et al., 2020; Böhnisch et al., 2020; Champagne et al., 2020) and positively contribute to the new science around large ensemble climate modelling.

Code and data availability. The raw model output, primary data, and code used to complete the analysis and create the figures can be accessed in the following locations.

- The data for the Canadian Earth System Model Large Ensembles can be accessed here: https://open.canada.ca/data/ en/dataset/aa7b6823-fd1e-49ff-a6fb-68076a4a477c (Kushner et al., 2018; Kirchmeier-Young et al., 2017). The GCM data can also be accessed at http://www.cesm.ucar.edu/projects/ community-projects/MMLEA/ (Deser et al., 2020).

- The ClimEx project data can be accessed from the Globus endpoint found in this location: https://www.climex-project.org/ en/data-access (Leduc et al., 2019).

- Primary data and scripts used in the analysis and other supporting information that may be useful in reproducing the author's work are archived by the Max Planck Institute for Meteorology and can be obtained by contacting publications@mpimet.mpg.de. 
Author contributions. All authors contributed to planning the content of the paper. NM wrote the paper and created the figures. SM computed the warming levels. SM and RL revised the paper.

Competing interests. The authors declare that they have no conflict of interest.

Special issue statement. This article is part of the special issue "Large Ensemble Climate Model Simulations: Exploring Natural Variability, Change Signals and Impacts”. It is a result of the EGU General Assembly 2019, Vienna, Austria, 7-12 April 2019.

Acknowledgements. We would like to thank Valerio Lucarini for his role as editor for this special issue and Axel Kleidon for editing this article. We would additionally like to thank all of the authors who submitted papers to this special issue and all reviewers who took the time to provide feedback on the papers. We thank the ClimEx project for providing the RCM data. The production of ClimEx was funded within the ClimEx project by the Bavarian State Ministry for the Environment and Consumer Protection. The CRCM5 was developed by the ESCER centre of Université du Québec à Montréal (UQAM; https://www.escer.uqam.ca, last access: 14 April 2020) in collaboration with Environment and Climate Change Canada. We acknowledge Environment and Climate Change Canada's Canadian Centre for Climate Modelling and Analysis for executing and making available the CanESM2 Large Ensemble simulations used in this study and the Canadian Sea Ice and Snow Evolution Network for proposing the simulations. Computations with the CRCM5 for the ClimEx project were made on the SuperMUC supercomputer at the Leibniz Supercomputing Centre (LRZ) of the Bavarian Academy of Sciences and Humanities. The operation of this supercomputer is funded via the Gauss Centre for Supercomputing (GCS) by the German Federal Ministry of Education and Research and the Bavarian State Ministry of Education, Science and the Arts. We thank Raul Wood for facilitating and providing the precipitation data for ClimEx. We additionally thank Dirk Notz for his internal review of the paper. Finally we thank Brianna Conrad and Bill Maher for their comments on this paper. Nicola Maher and Sebastian Milinski were supported by the Max Planck Society for the Advancement of Science.

Financial support. The article processing charges for this openaccess publication were covered by the Max Planck Society.

Review statement. This paper was edited by Axel Kleidon.

\section{References}

Aalbers, E., Lenderink, G., van Meijgaard, E., and van den Hurk, B.: Local-scale changes in mean and heavy precipitation in Western Europe, climate change or internal variability?, Clim. Dynam., 40, 4745-4766, https://doi.org/10.1007/s00382-017-39019, 2018.
Allen, M., Dube, O., Solecki, W., Aragón-Durand, F., Cramer, W., Humphreys, S., Kainuma, M., Kala, J., Mahowald, N., Mulugetta, Y., Perez, R., Wairiu, M., and Zickfeld, K.: Framing and Context, in: Global Warming of $1.5^{\circ} \mathrm{C}$. An IPCC Special Report on the impacts of global warming of $1.5^{\circ} \mathrm{C}$ above pre-industrial levels and related global greenhouse gas emission pathways, in the context of strengthening the global response to the threat of climate change, sustainable development, and efforts to eradicate poverty, edited by: Masson-Delmotte, V., Zhai, P., Pörtner, H.-O., Roberts, D., Skea, J., Shukla, P., Pirani, A., Moufouma-Okia, W., Péan, C., Pidcock, R., Connors, S., Matthews, J., Chen, Y., Zhou, X., Gomis, M., Lonnoy, E., Maycock, T., Tignor, M., and Waterfield, T., in press, 2018.

Barnett, T. P., Arpe, K., Bengtsson, L., Ji, M., and Kumar, A.: Potential Predictability and AMIP Implications of Midlatitude Climate Variability in Two General Circulation Models, J. Climate, 10, 2321-2329, https://doi.org/10.1175/15200442(1997)010<2321:PPAAIO>2.0.CO;2, 1997.

Bittner, M., Schmidt, H., Timmreck, C., and Sienz, F.: Using a large ensemble of simulations to assess the Northern Hemisphere stratospheric dynamical response to tropical volcanic eruptions and its uncertainty, Geophys. Res. Lett., 43, 93249332, https://doi.org/10.1002/2016GL070587, 2016.

Böhnisch, A., Ludwig, R., and Leduc, M.: Using a nested single-model large ensemble to assess the internal variability of the North Atlantic Oscillation and its climatic implications for central Europe, Earth Syst. Dynam., 11, 617-640, https://doi.org/10.5194/esd-11-617-2020, 2020.

Branstator, G. and Selten, F.: "Modes of Variability" and Climate Change, J. Climate, 22, 2639-2658, https://doi.org/10.1175/2008JCLI2517.1, 2009.

Champagne, O., Leduc, M., Coulibaly, P., and Arain, M. A.: Winter hydrometeorological extreme events modulated by large-scale atmospheric circulation in southern Ontario, Earth Syst. Dynam., 11, 301-318, https://doi.org/10.5194/esd-11-301-2020, 2020.

Christensen, O. and Kjellström, E.: Partitioning uncertainty components of mean climate and climate change in a large ensemble of European regional climate model projections, Clim. Dynam., 54, 4293-4308, https://doi.org/10.1007/s00382-020-05229-y, 2020.

Dai, A. and Bloecker, C. E.: Impacts of internal variability on temperature and precipitation trends in large ensemble simulations by two climate models, Clim. Dynam., 52, 289-306, https://doi.org/10.1007/s00382-018-4132-4, 2019.

Deser, C., Laurent, T., and Phillips, A.: Forced and Internal Components of Winter Air Temperature Trends over North America during the past 50 Years: Mechanisms and Implications, J. Climate, 29, 2237-2258, https://doi.org/10.1175/JCLI-D-150304.1, 2016.

Deser, C., Lehner, F., Rodgers, K. B., Ault, T., Delworth, T., DiNezio, P., Fiore, A., Frankignoul, C., Fyfe, J., Horton, D., Kay, J. E., Knutti, R., Lovenduski, N., Marotzke, J., McKinnon, K., Minobe, S., Randerson, J., Screen, J., Simpson, I., and Ting, A.: Strength in Numbers: The Utility of Large Ensembles with Multiple Earth System Models, Nat. Clim. Change, https://doi.org/10.1038/s41558-020-0731-2, 2020 (data available at: http://www.cesm.ucar.edu/projects/community-projects/ MMLEA/, last access: 14 April 2020).

Di Luca, A., de Elía, R., and Laprise, R.: Potential for small scale added value of RCM's downscaled climate change signal, 
Clim. Dynam., 40, 601-618, https://doi.org/10.1007/s00382012-1415-z, 2013.

Diffenbaugh, N. S., Swain, D. L., and Touma, D.: Anthropogenic warming has increased drought risk in California, P. Natl. Acad. Sci. USA, 112, 3931-3936, https://doi.org/10.1073/pnas.1422385112, 2015.

Dittus, A., Hawkins, E., Wilcox, L., Sutton, R., Smith, C., Andrews, M., and Forster, P.: Sensitivity of historical climate simulations to uncertain aerosol forcing, Geophys. Res. Lett., 47, e2019GL085806, https://doi.org/10.1029/2019GL085806, 2020.

Dudhia, J.: A history of mesoscale model development, Asia-Pac. J. Atmos. Sci., 50, 121-131, https://doi.org/10.1007/s13143-0140031-8, 2014.

Díaz, L. B., Saurral, R. I., and Vera, C. S.: Assessment of South America summer rainfall climatology and trends in a set of global climate models large ensembles, Int. J. Climatol., 41, E59-E77, https://doi.org/10.1002/joc.6643, 2021.

Ehmele, F., Kautz, L.-A., Feldmann, H., and Pinto, J. G.: Longterm variance of heavy precipitation across central Europe using a large ensemble of regional climate model simulations, Earth Syst. Dynam., 11, 469-490, https://doi.org/10.5194/esd-11-4692020, 2020.

Evans, J. and McCabe, M.: Effect of model resolution on a regional climate model simulation over southeast Australia, Clim. Res., 56, 131-145, https://doi.org/10.3354/cr01151, 2013.

Fasullo, J. T. and Nerem, R. S.: Interannual Variability in Global Mean Sea Level Estimated from the CESM Large and Last Millennium Ensembles, Water, 8, 491, https://doi.org/10.3390/w8110491, 2016.

Fasullo, J. T., Phillips, A. S., and Deser, C.: Evaluation of Leading Modes of Climate Variability in the CMIP Archives, J. Climate, 33, 5527-5545, https://doi.org/10.1175/JCLI-D-191024.1, 2020.

Feser, F., Rockel, B., von Storch, H., Winterfeldt, J., and Zahn, M.: Regional Climate Models Add Value to Global Model Data: A Review and Selected Examples:, B. Am. Meteorol. Soc., 92, 1181-1192, https://doi.org/10.1175/2011BAMS3061.1, 2011.

Fischer, E., Beyerle, U., and Knutti, R.: Robust spatially aggregated projections of climate extremes, Nat. Clim. Change, 3, 10331038, 2013.

Fischer, E. M., Luterbacher, J., Zorita, E., Tett, S. F. B., Casty, C., and Wanner, H.: European climate response to tropical volcanic eruptions over the last half millennium, Geophys. Res. Lett., 34, L05707, https://doi.org/10.1029/2006GL027992, 2007.

Frankignoul, C., Gastineau, G., and Kwon, Y.-O.: Estimation of the SST Response to Anthropogenic and External Forcing and Its Impact on the Atlantic Multidecadal Oscillation and the Pacific Decadal Oscillation, J. Climate, 30, 9871-9895, https://doi.org/10.1175/JCLI-D-17-0009.1, 2017.

Gagné, M.-È., Fyfe, J. C., Gillett, N. P., Polyakov, I. V., and Flato, G. M.: Aerosol-driven increase in Arctic sea ice over the middle of the twentieth century, Geophys. Res. Lett., 44, 7338-7346, https://doi.org/10.1002/2016GL071941, 2017a.

Gagné, M.-È., Kirchmeier-Young, M. C., Gillett, N. P., and Fyfe, J. C.: Arctic sea ice response to the eruptions of Agung, El Chichón, and Pinatubo, J. Geophys. Res.-Atmos., 122, 80718078, https://doi.org/10.1002/2017JD027038, 2017b.

Gates, W. L.: AN AMS CONTINUING SERIES: GLOBAL CHANGE-AMIP: The Atmospheric
Model Intercomparison Project, B. Am. Meteorol. Soc., 73, 1962-1970, https://doi.org/10.1175/15200477(1992)073<1962:ATAMIP>2.0.CO;2, 1992.

Gibson, P., Perkins-Kirkpatrick, S., Alexander, L., and Fischer, E.: Comparing Australian heat waves in the CMIP5 models through cluster analysis, J. Geophys. Res.-Atmos., 122, 32663281, 2017.

Haszpra, T., Herein, M., and Bódai, T.: Investigating ENSO and its teleconnections under climate change in an ensemble view - a new perspective, Earth Syst. Dynam., 11, 267-280, https://doi.org/10.5194/esd-11-267-2020, 2020a.

Haszpra, T., Topál, D., and Herein, M.: On the time evolution of the Arctic Oscillation and related wintertime phenomena under different forcing scenarios in an ensemble approach, J. Climate, 33, 3107-3124, https://doi.org/10.1175/JCLI-D-19-0004.1, 2020b.

Haugen, M. A., Stein, M. L., Moyer, E. J., and Sriver, R. L.: Estimating Changes in Temperature Distributions in a Large Ensemble of Climate Simulations Using Quantile Regression, J. Climate, 31, 8573-8588, https://doi.org/10.1175/JCLI-D-170782.1, 2018.

Hawkins, E. and Sutton, R.: Decadal predictability of the Atlantic Ocean in a coupled GCM: forecast skill and optimal perturbations using linear inverse modeling, J. Climate, 22, 3960-3978, https://doi.org/10.1175/2009JCLI2720.1, 2009.

Herein, M., Drótos, G., Haszpra, T., Márfy, and Tél, T.: The theory of parallel climate realizations as a new framework for teleconnection analysis, Sci. Rep.-UK, 7, 44529, https://doi.org/10.1038/srep44529, 2017.

Jacob, D., Kotova, L., Teichmann, C., Sobolowski, S. P., Vautard, R., Donnelly, C., Koutroulis, A. G., Grillakis, M. G., Tsanis, I. K., Damm, A., Sakalli, A., and van Vliet, M. T. H.: Climate Impacts in Europe Under $+1.5^{\circ} \mathrm{C}$ Global Warming, Earth's Future, 6, 264-285, https://doi.org/10.1002/2017EF000710, 2018.

Jacob, D., Teichmann, C., Sobolowski, S., Katragkou, E., Anders, I., Belda, M., Benestad, R., Boberg, F., Buonomo, E., Cardoso, R. M., Casanueva, A., Christensen, O. B., Christensen, J. H., Coppola, E., De Cruz, L., Davin, E. L., Dobler, A., Domínguez, M., Fealy, R., Fernandez, J., Gaertner, M. A., García-Díez, M., Giorgi, F., Gobiet, A., Goergen, K., Gómez-Navarro, J. J., Alemán, J. J. G., Gutiérrez, C., Gutiérrez, J. M., Güttler, I., Haensler, A., Halenka, T., Jerez, S., Jiménez-Guerrero, P., Jones, R. G., Keuler, K., Kjellström, E., Knist, S., Kotlarski, S., Maraun, D., van Meijgaard, E., Mercogliano, P., Montávez, J. P., Navarra, A., Nikulin, G., de Noblet-Ducoudré, N., Panitz, H.-J., Pfeifer, S., Piazza, M., Pichelli, E., Pietikäinen, J.-P., Prein, A. F., Preuschmann, S., Rechid, D., Rockel, B., Romera, R., Sánchez, E., Sieck, K., Soares, P. M. M., Somot, S., Srnec, L., Sørland, S. L., Termonia, P., Truhetz, H., Vautard, R., Warrach-Sagi, K., and Wulfmeyer, V.: Regional climate downscaling over Europe: perspectives from the EURO-CORDEX community, Reg. Environ. Change, 20, 51, https://doi.org/10.1007/s10113-020-016069, 2020.

Kay, J. E., Deser, C., Phillips, A., Mai, A., Hannay, C., Strand, G., Arblaster, J. M., Bates, S. C., Danabasoglu, G., Edwards, J., Holland, M., Kushner, P., Lamarque, J.-F., Lawrence, D., Lindsay, K., Middleton, A., Munoz, E., Neale, R., Oleson, K., Polvani, L., and Vertenstein, M.: The Community Earth System Model (CESM) Large Ensemble Project: A Community Resource for Studying Climate Change in the Presence of Inter- 
nal Climate Variability, B. Am. Meteorol. Soc., 96, 1333-1349, https://doi.org/10.1175/BAMS-D-13-00255.1, 2015.

Kirchmeier-Young, M., Zwiers, F., and Gillett, N.: Attribution of Extreme Events in Arctic Sea Ice Extent, J. Climate, 30, 553-571, https://doi.org/10.1175/JCLI-D-16-0412.1, 2017 (data available at: https://open.canada.ca/data/en/ dataset/aa7b6823-fd1e-49ff-a6fb-68076a4a477c, last access: 14 April 2020).

Kirchmeier-Young, M. C., Gillett, N. P., Zwiers, F. W., Cannon, A. J., and Anslow, F. S.: Attribution of the Influence of HumanInduced Climate Change on an Extreme Fire Season, Earth's Future, 7, 2-10, https://doi.org/10.1029/2018EF001050, 2019.

Krumhardt, K. M., Lovenduski, N. S., Long, M. C., and Lindsay, K.: Avoidable impacts of ocean warming on marine primary production: Insights from the CESM ensembles, Global Biogeochem. Cy., 31, 114-133, https://doi.org/10.1002/2016GB005528, 2017.

Kushner, P. J., Mudryk, L. R., Merryfield, W., Ambadan, J. T., Berg, A., Bichet, A., Brown, R., Derksen, C., Déry, S. J., Dirkson, A., Flato, G., Fletcher, C. G., Fyfe, J. C., Gillett, N., Haas, C., Howell, S., Laliberté, F., McCusker, K., Sigmond, M., Sospedra-Alfonso, R., Tandon, N. F., Thackeray, C., Tremblay, B., and Zwiers, F. W.: Canadian snow and sea ice: assessment of snow, sea ice, and related climate processes in Canada's Earth system model and climate-prediction system, The Cryosphere, 12, 1137-1156, https://doi.org/10.5194/tc-121137-2018, 2018 (data available at: https://open.canada.ca/data/ en/dataset/aa7b6823-fd1e-49ff-a6fb-68076a4a477c, last access: 14 April 2020).

Landrum, L. and Holland, M.: Extremes become routine in an emerging new Arctic, Nat. Clim. Change, 10, 1108-1115, https://doi.org/10.1038/s41558-020-0892-z, 2020.

Lang, A. and Mikolajewicz, U.: Rising extreme sea levels in the German Bight under enhanced $\mathrm{CO}_{2}$ levels: a regionalized large ensemble approach for the North Sea, Clim. Dynam., 55, 18291842, https://doi.org/10.1007/s00382-020-05357-5, 2020.

Leduc, M., Laprise, R., de Elía, R., and Šeparović, L.: Is Institutional Democracy a Good Proxy for Model Independence?, J. Climate, 29, 8301-8316, https://doi.org/10.1175/JCLI-D-150761.1, 2016.

Leduc, M., Mailhot, A., Frigon, A., Martel, J.-L., Ludwig, R., Brietzke, G. B., Giguère, M., Brissette, F., Turcotte, R., Braun, M., and Scinocca, J.: The ClimEx Project: A 50-Member Ensemble of Climate Change Projections at 12-km Resolution over Europe and Northeastern North America with the Canadian Regional Climate Model (CRCM5), J. Appl. Meteorol. Clim., 58, 663-693, https://doi.org/10.1175/JAMC-D-180021.1, 2019 (data available at: https://www.climex-project.org/ en/data-access, last access: 14 April 2020).

Lehner, F., Deser, C., and Sanderson, B.: Future risk of recordbreaking summer temperatures and its mitigation, Climatic Change, 145, 363-375, 2016.

Lehner, F., Deser, C., and Terray, L.: Toward a New Estimate of "Time of Emergence" of Anthropogenic Warming: Insights from Dynamical Adjustment and a Large Initial-Condition Model Ensemble, J. Climate, 30, 7739-7756, 2017.

Lehner, F., Deser, C., Maher, N., Marotzke, J., Fischer, E. M., Brunner, L., Knutti, R., and Hawkins, E.: Partitioning climate projection uncertainty with multiple large ensembles and CMIP5/6,
Earth Syst. Dynam., 11, 491-508, https://doi.org/10.5194/esd11-491-2020, 2020.

Li, H. and Ilyina, T.: Current and Future Decadal Trends in the Oceanic Carbon Uptake Are Dominated by Internal Variability, Geophys. Res. Lett., 45, 916-925, https://doi.org/10.1002/2017GL075370, 2018.

Liguori, G., McGregor, S., Arblaster, J. M., Singh, M. S., and Meehl, G. A.: A joint role for forced and internally-driven variability in the decadal modulation of global warming, Nat. Commun., 11, 3827, https://doi.org/10.1038/s41467-020-176837, 2020.

Liu, F., Li, J., Wang, B., Liu, J., Li, T., Huang, G., and Wang, Z.: Divergent El Niño responses to volcanic eruptions at different latitudes over the past millennium, Clim. Dynam., 50, 3799-3812, https://doi.org/10.1007/s00382-017-3846-z, 2018.

Lovenduski, N. S., McKinley, G. A., Fay, A. R., Lindsay, K., and Long, M. C.: Partitioning uncertainty in ocean carbon uptake projections: Internal variability, emission scenario, and model structure, Global Biogeochem. Cy., 30, 1276-1287, https://doi.org/10.1002/2016GB005426, 2016.

Lucas-Picher, P., Laprise, R., and Winger, K.: Evidence of added value in North American regional climate model hindcast simulations using ever-increasing horizontal resolutions, Clim. Dynam., 48, 2611-2633, https://doi.org/10.1007/s00382-016-3227z, 2017.

Maher, N., McGregor, S., England, M. H., and Sen Gupta, A.: Effects of volcanism on tropical variability, Geophys. Res. Lett., 42, 6024-6033, 2015.

Maher, N., Matei, D., Milinski, S., and Marotzke, J.: ENSO Change in Climate Projections: Forced Response or Internal Variability?, Geophys. Res. Lett., 45, 11390-11398, https://doi.org/10.1029/2018GL079764, 2018.

Maher, N., Milinski, S., Suarez-Gutierrez, L., Botzet, M., Dobrynin, M., Kornblueh, L., Kröger, J., Takano, Y., Ghosh, R., Hedemann, C., Li, C., Li, H., Manzini, E., Notz, D., Putrasahan, D., Boysen, L., Claussen, M., Ilyina, T., Olonscheck, D., Raddatz, T., Stevens, B., and Marotzke, J.: The Max Planck Institute Grand Ensemble: Enabling the Exploration of Climate System Variability, J. Adv. Model. Earth Sy., 11, 2050-2069, https://doi.org/10.1029/2019MS001639, 2019.

Maher, N., Lehner, F., and Marotzke, J.: Quantifying the role of internal variability in the temperature we expect to observe in the coming decades, Environ. Res. Lett., 15, 054014, https://doi.org/10.1088/1748-9326/ab7d02, 2020.

Maher, N., Power, S., and Marotzke, J.: More accurate quantification of model-to-model agreement in externally forced climatic responses over the coming century, Nat. Commun., 12, 788, https://doi.org/10.1038/s41467-020-20635-w, 2021.

Mankin, J. S., Lehner, F., Coats, S., and McKinnon, K. A.: The Value of Initial Condition Large Ensembles to Robust Adaptation Decision-Making, Earth's Future, 8, e2012EF001610, https://doi.org/10.1029/2020EF001610, 2020.

Marotzke, J.: Quantifying the irreducible uncertainty in nearterm climate projections, WIREs Climate Change, 10, e563, https://doi.org/10.1002/wcc.563, 2019.

Martynov, A., Laprise, R., Sushama, L., Winger, K., Šeparović, L., and Dugas, B.: Reanalysis-driven climate simulation over CORDEX North America domain using the Canadian Regional Climate Model, version 5: model performance evaluation, 
Clim. Dynam., 41, 2073-3005, https://doi.org/10.1007/s00382013-1778-9, 2013.

McKinley, G. A., Pilcher, D. J., Fay, A. R., Lindsay, K., Long, M. C., and Lovenduski, N. S.: Timescales for detection of trends in the ocean carbon sink, Nature, 530, 469-472, https://doi.org/10.1038/nature16958, 2016.

McKinnon, K. A. and Deser, C.: Internal Variability and Regional Climate Trends in an Observational Large Ensemble, J. Climate, 31, 6783-6802, https://doi.org/10.1175/JCLI-D-170901.1, 2018.

McKinnon, K. A., Poppick, A., Dunn-Sigouin, E., and Deser, C.: An "Observational Large Ensemble" to Compare Observed and Modeled Temperature Trend Uncertainty due to Internal Variability, J. Climate, 30, 7585-7598, https://doi.org/10.1175/JCLID-16-0905.1, 2017.

Mearns, L. O., Sain, S., Leung, L. R., Bukovsky, M. S., McGinnis, S., Biner, S., Caya, D., Arritt, R. W., Gutowski, W., Takle, E., Snyder, M., Jones, R. G., Nunes, A. M. B., Tucker, S., Herzmann, D., McDaniel, L., and Sloan, L.: Climate change projections of the North American Regional Climate Change Assessment Program (NARCCAP), Climatic Change, 120, 965-975, https://doi.org/10.1007/s10584-013-0831-3, 2013.

Merrifield, A. L., Brunner, L., Lorenz, R., Medhaug, I., and Knutti, R.: An investigation of weighting schemes suitable for incorporating large ensembles into multi-model ensembles, Earth Syst. Dynam., 11, 807-834, https://doi.org/10.5194/esd-11-807-2020, 2020.

Milinski, S., Maher, N., and Olonscheck, D.: How large does a large ensemble need to be?, Earth Syst. Dynam., 11, 885-901, https://doi.org/10.5194/esd-11-885-2020, 2020.

Mittermeier, M., Braun, M., Hofstätter, M., Wang, Y., and Ludwig, R.: Detecting Climate Change Effects on Vb-cyclones in a 50Member Single-Model Ensemble using Machine Learning., Geophys. Res. Lett., 46, 14653-14661, 2019.

Olonscheck, D., Rugenstein, M., and Marotzke, J.: Broad Consistency Between Observed and Simulated Trends in Sea Surface Temperature Patterns, Geophys. Res. Lett., 47, e2019GL086773, https://doi.org/10.1029/2019GL086773, 2020.

Pausata, F. S. R., Grini, A., Caballero, R., Hannachi, A., and Seland, Ø.: High-latitude volcanic eruptions in the Norwegian Earth System Model: the effect of different initial conditions and of the ensemble size, Tellus B, 67, 26728, https://doi.org/10.3402/tellusb.v67.26728, 2015.

Pendergrass, A. G., Coleman, D. B., Deser, C., Lehner, F., Rosenbloom, N., and Simpson, I. R.: Nonlinear Response of Extreme Precipitation to Warming in CESM1, Geophys. Res. Lett., 46, 10551-10560, https://doi.org/10.1029/2019GL084826, 2019.

Penduff, T., Barnier, B., Terray, L., Sérazin, G., Gregorio, S., Brankart, J.-M., Moine, M.-P., Molines, J.-M., and Brasseur, P.: Ensembles of eddying ocean simulations for climate, Vol. 65, InternationalCLIVAR Project Office, Southampton, United Kingdom, 19-22, 2014.

Poschlod, B., Willkofer, F., and Ludwig, R.: Impact of climate change on the hydrological regimes in Bavaria, Water, 12, 1599, https://doi.org/10.3390/w12061599, 2020a.

Poschlod, B., Zscheischler, J., Wood, R., Sillmann, J., and Ludwig, R.: Climate Change Effects on hydrometeorological compound events over Southern Norway, Weather and Climate Extremes, 28, https://doi.org/10.1016/j.wace.2020.100253, 2020 b.
Rodgers, K. B., Lin, J., and Frölicher, T. L.: Emergence of multiple ocean ecosystem drivers in a large ensemble suite with an Earth system model, Biogeosciences, 12, 3301-3320, https://doi.org/10.5194/bg-12-3301-2015, 2015.

Rummukainen, M.: State-of-the-art with regional climate models, WIREs Clim. Change, 1, 82-96, https://doi.org/10.1002/wcc.8, 2010.

Rummukainen, M.: Added value in regional climate modeling, WIREs Clim. Change, 7, 145-159, https://doi.org/10.1002/wcc.378, 2016.

Sanderson, B. M., Oleson, K. W., Strand, W. G., Lehner, F., and O'Neill, B. C.: A new ensemble of GCM simulations to assess avoided impacts in a climate mitigation scenario, Climatic Change, 146, 303-318, https://doi.org/10.1007/s10584015-1567-z, 2018.

Santer, B. D., Fyfe, J. C., Solomon, S., Painter, J. F., Bonfils, C., Pallotta, G., and Zelinka, M. D.: Quantifying stochastic uncertainty in detection time of human-caused climate signals, P. Natl. Acad. Sci. USA, 116, 19821-19827, https://doi.org/10.1073/pnas.1904586116, 2019.

Schlunegger, S., Rodgers, K., and Sarmiento, J.: Emergence of anthropogenic signals in the ocean carbon cycle, Nat. Clim. Change, 9, 719-725, https://doi.org/10.1038/s41558-019-05532, 2019.

Schlunegger, S., Rodgers, K. B., Sarmiento, J. L., Ilyina, T., Dunne, J., Takano, Y., Christian, J., Long, M., Frölicher, T. L., Slater, R., and Lehner, F.: Time of Emergence \& Large Ensemble intercomparison for ocean biogeochemical trends, Global Biogeochem. Cy., 34, e2019GB006453, https://doi.org/10.1029/2019GB006453, 2020.

Shiogama, H., Hirata, R., Hasegawa, T., Fujimori, S., Ishizaki, N. N., Chatani, S., Watanabe, M., Mitchell, D., and Lo, Y. T. E.: Historical and future anthropogenic warming effects on droughts, fires and fire emissions of $\mathrm{CO}_{2}$ and $\mathrm{PM}_{2.5}$ in equatorial Asia when 2015-like El Niño events occur, Earth Syst. Dynam., 11, 435-445, https://doi.org/10.5194/esd-11-435-2020, 2020.

Sippel, S., Meinshausen, N., Fischer, E., Székely, E., and Knutti, R.: Climate change now detectable from any single day of weather at global scale, Nat. Clim. Change, 10, 35-41, https://doi.org/10.1038/s41558-019-0666-7, 2020.

Smith, A. and Jahn, A.: Definition differences and internal variability affect the simulated Arctic sea ice melt season, The Cryosphere, 13, 1-20, https://doi.org/10.5194/tc-13-1-2019, 2019.

Spring, A. and Ilyina, T.: Predictability horizons in the global carbon cycle inferred from a perfect-model framework, Geophys. Res. Lett., 47, e2019GL085311, https://doi.org/10.1029/2019GL085311, 2020.

Stolpe, M. B., Medhaug, I., Sedláček, J., and Knutti, R.: Multidecadal Variability in Global Surface Temperatures Related to the Atlantic Meridional Overturning Circulation, J. Climate, 31, 2889-2906, https://doi.org/10.1175/JCLI-D-17-0444.1, 2018.

Suarez-Gutierrez, L., Li, C., Müller, W. A., and Marotzke, J.: Internal variability in European summer temperatures at $1.5^{\circ} \mathrm{C}$ and $2{ }^{\circ} \mathrm{C}$ of global warming, Environ. Res. Lett., 13, 064026, https://doi.org/10.1088/1748-9326/aaba58, 2018.

Tebaldi, C. and Wehner, M.: Benefits of mitigation for future heat extremes under RCP4.5 compared to RCP8.5, Cli- 
matic Change, 146, 349-361, https://doi.org/10.1007/s10584016-1605-5, 2018.

Topál, D., Hatvani, I., and Kern, Z.: Refining projected multidecadal hydroclimate uncertainty in East-Central Europe using CMIP5 and single-model large ensemble simulations, Theor. Appl. Climatol., 142, 1147-1167, https://doi.org/10.1007/s00704-02003361-7, 2020.

van der Wiel, K., Wanders, N., Selten, F. M., and Bierkens, M. F. P.: Added Value of Large Ensemble Simulations for Assessing Extreme River Discharge in a $2^{\circ} \mathrm{C}$ Warmer World, Geophys. Res. Lett., 46, 2093-2102, https://doi.org/10.1029/2019GL081967, 2019.

von Trentini, F., Leduc, M., and Ludwig, R.: Assessing natural variability in RCM signals: comparison of a multi model EURO-CORDEX ensemble with a 50-member single model large ensemble, Clim. Dynam., 53, 1963-1979, https://doi.org/10.1007/s00382-019-04755-8, 2019.

von Trentini, F., Aalbers, E. E., Fischer, E. M., and Ludwig, R.: Comparing interannual variability in three regional single-model initial-condition large ensembles (SMILEs) over Europe, Earth Syst. Dynam., 11, 1013-1031, https://doi.org/10.5194/esd-111013-2020, 2020.

Wang, S.-Y. S., Zhao, L., Yoon, J.-H., Klotzbach, P., and Gillies, R. R.: Quantitative attribution of climate effects on Hurricane Harvey's extreme rainfall in Texas, Environ. Res. Lett., 13, 054014, https://doi.org/10.1088/1748-9326/aabb85, 2018.

Ward, B., Pausata, F. S. R., and Maher, N.: The sensitivity of the ENSO to volcanic aerosol spatial distribution in the MPI large ensemble, Earth Syst. Dynam. Discuss. [preprint], https://doi.org/10.5194/esd-2020-63, in review, 2020.

Watanabe, M., Suzuki, T., O'ishi, R., Komuro, Y., Watanabe, S., Emori, S., Takemura, T., Chikira, M., Ogura, T., Sekiguchi, M., Takata, K., Yamazaki, D., Yokohata, T., Nozawa, T., Hasumi, H., Tatebe, H., and Kimoto, M.: Improved Climate Simulation by MIROC5: Mean States, Variability, and Climate Sensitivity, J. Climate, 23, 6312-6335, https://doi.org/10.1175/2010JCLI3679.1, 2010.
Willibald, F., Kotlarski, S., Grêt-Regamey, A., and Ludwig, R.: Anthropogenic climate change versus internal climate variability: impacts on snow cover in the Swiss Alps, The Cryosphere, 14, 2909-2924, https://doi.org/10.5194/tc-14-2909-2020, 2020.

Willkofer, F., Wood, R. R., von Trentini, F., Weismüller, J., Poschlod, B., and Ludwig, R.: A Holistic Modelling Approach for the Estimation of Return Levels of Peak Flows in Bavaria, Water, 12, 2349, https://doi.org/10.3390/w12092349, 2020.

Wills, R., Battisti, D., and Armour, K.: Pattern recognition methods to separate forced responses from internal variability in climate model ensembles and observations, J. Climate, 33, 8693-8719, 2020.

Wood, R. and Ludwig, R.: Analyzing Internal Variability and Forced Response of Sub-daily and Daily Extreme Precipitation over Europe, Geophys. Res. Lett., 47, e2020GL089300, https://doi.org/10.1029/2020GL089300, 2020.

Zelle, H., Jan van Oldenborgh, G., Burgers, G., and Dijkstra, H.: El Niño and Greenhouse Warming: Results from Ensemble Simulations with the NCAR CCSM, J. Climate, 18, 4669-4683, https://doi.org/10.1175/JCLI3574.1, 2005.

Zhou, T., Lu, J., Zhang, W., and Chen, Z.: The Sources of Uncertainty in the Projection of Global Land Monsoon Precipitation, Geophys. Res. Lett., 47, e2020GL088415, https://doi.org/10.1029/2020GL088415, 2020.

Zscheischler, J., Westra, S., van den Hurk, B. J. J. M., Seneviratne, S. I., Ward, P. J., Pitman, A., AghaKouchak, A., Bresch, D. N., Leonard, M., Wahl, T., and Zhang, X.: Future climate risk from compound events, Nat. Clim. Change, 8, 469-477, 2018.

Zuo, M., Man, W., and Zhou, T., and Guo, Z.: Different impacts of Northern, tropical, and Southern volcanic eruptions on the tropical pacific SST in the Last Millennium, J. Climate, 31, 67296744, https://doi.org/10.1175/JCLI-D-17-0571.1, 2018.

Šeparović, L., Alexandru, A., Laprise, R., Martynov, A., Sushama, L., Winger, K., Tete, K., and Valin, M.: Present climate and climate change over North America as simulated by the fifthgeneration Canadian regional climate model, Clim. Dynam., 41, 3167-3201, https://doi.org/10.1007/s00382-013-1737-5, 2013. 